Quality and Price Personalization under Customer Recognition: A Dynamic Monopoly Model

\section{CIRANO}

Allier savoir et décision

DIDIER LAUSSEL NGO VAN LONG JOANA RESENDE 
2019s-03

\title{
Quality and Price Personalization under Customer Recognition: A Dynamic Monopoly Model
}

\author{
Didier Laussel, Ngo Van Long, Joana Resende
}

\section{Série Scientifique \\ Scientific Series}

\author{
Montréal \\ Février/February 2019
}

(C) 2019 Didier Laussel, Ngo Van Long, Joana Resende. Tous droits réservés. All rights reserved. Reproduction partielle permise avec citation du document source, incluant la notice $\mathbb{C}$. Short sections may be quoted without explicit permission, if full credit, including $@$ notice, is given to the source.

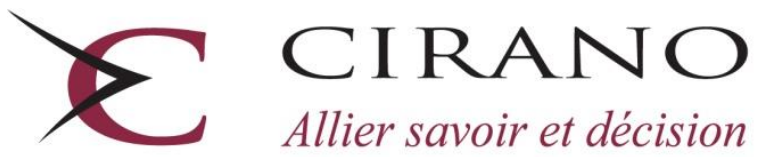

Centre interuniversitaire de recherche en analyse des organisations 


\section{CIRANO}

Le CIRANO est un organisme sans but lucratif constitué en vertu de la Loi des compagnies du Québec. Le financement de son infrastructure et de ses activités de recherche provient des cotisations de ses organisations-membres, d'une subvention d'infrastructure du gouvernement du Québec, de même que des subventions et mandats obtenus par ses équipes de recherche.

CIRANO is a private non-profit organization incorporated under the Quebec Companies Act. Its infrastructure and research activities are funded through fees paid by member organizations, an infrastructure grant from the government of Quebec, and grants and research mandates obtained by its research teams.

\section{Les partenaires du CIRANO}

\section{Partenaires corporatifs}

Autorité des marchés financiers

Banque de développement du Canada

Banque du Canada

Banque Laurentienne

Banque Nationale du Canada

Bell Canada

BMO Groupe financier

Caisse de dépôt et placement du Québec

Canada Manuvie

Énergir

Hydro-Québec

Innovation, Sciences et Développement économique Canada

Intact Corporation Financière

Investissements PSP

Ministère de l'Économie, de la Science et de l'Innovation

Ministère des Finances du Québec

Mouvement Desjardins

Power Corporation du Canada

Rio Tinto

Ville de Montréal

\section{Partenaires universitaires}

École de technologie supérieure

École nationale d'administration publique

HEC Montréal

Institut national de la recherche scientifique

Polytechnique Montréal

Université Concordia

Université de Montréal

Université de Sherbrooke

Université du Québec

Université du Québec à Montréal

Université Laval

Université McGill

Le CIRANO collabore avec de nombreux centres et chaires de recherche universitaires dont on peut consulter la liste sur son site web.

Les cahiers de la série scientifique (CS) visent à rendre accessibles des résultats de recherche effectuée au CIRANO afin de susciter échanges et commentaires. Ces cahiers sont écrits dans le style des publications scientifiques. Les idées et les opinions émises sont sous l'unique responsabilité des auteurs et ne représentent pas nécessairement les positions du CIRANO ou de ses partenaires.

This paper presents research carried out at CIRANO and aims at encouraging discussion and comment. The observations and viewpoints expressed are the sole responsibility of the authors. They do not necessarily represent positions of CIRANO or its partners.

ISSN 2292-0838 (en ligne) 


\title{
Quality and Price Personalization under Customer Recognition: A Dynamic Monopoly Model
}

\author{
Didier Laussel *, Ngo Van Long ${ }^{*}$, Joana Resende *
}

\begin{abstract}
Résumé
Nous présentons un modèle d'hyper-segmentation du marché, dans lequel une entreprise monopoliste utilise les technologies de l'information pour acquérir, en une période, toutes les informations relatives aux préférences des consommateurs qui achètent ses produits différenciés verticalement au cours de cette période. Les consommateurs dont la préférence pour la qualité est faible ont l'intérêt à reporter leurs achats à la période suivante afin d'obtenir une offre de qualité supérieure (sans distorsion). Le monopoleur contrecarre cette intention en proposant des primes d'information plus élevés. Nous analysons le jeu dynamique entre le monopoleur et ses clients. Nous constatons que dans un équilibre parfait de Markov, l'entreprise élargit progressivement le marché. Le marché n'est pas couvert en un clin d'œil, c'est-à-dire que la dynamique n'est pas coasienne. En outre, contrairement au résultat coasien pour un monopole sur les biens durables, nous constatons que le profit de notre monopole sur les biens non durables augmente à mesure que l'intervalle d'engagement diminue. Le modèle entraîne certaines implications pour les politiques réglementaires en matière de collecte d'informations et de période d'engagement.
\end{abstract}

Mots clés : La dynamique coasienne, La collecte d'information, Monopole, Politiques réglementaires

Codes JEL : L12, L15

\begin{abstract}
We present a model of hyper-segmentation of market, where a monopolist firm uses information technology to acquire, in one period, all the information about the preferences of consumers who purchase its vertically differentiated products within that period. Lower consumer types have an incentive to delay their purchases until next period in order to obtain a higher (and non-distorted) quality offer. The monopolist counters this incentive by offering higher informational rents. We analyse the dynamic game between the monopolist and the customers. We find that in a Markov perfect equilibrium, the firm expands the market progressively. The market is not covered in a twinkle of an eye, i.e., the dynamics is nonCoasian. Also, contrary to the Coasian result for a durable-good monopoly, we find that the profit of our non-durable good monopoly increases as the interval of commitment shrinks. The model yields some implications for regulatory policies regarding information collection and commitment period.
\end{abstract}

Keywords: Coasian Dynamics, Information Collection, Monopoly, Regulatory Policies

JEL Codes: L12, L15

\footnotetext{
${ }^{*}$ Aix-Marseille University (Aix-Marseille School of Economics), CNRS \& EHESS. Email: Didier.laussel@outlook.fr

${ }^{\dagger}$ Corresponding Author. Affiliation: Department of Economics, McGill University. Postal address:McGill University - Economis, 855 Sherbrooke St. W., Montreal, Quebec, H3A 2T7. Email: ngo.long@mcgill.ca

$\$$ Cef.up, Economics Department, University of Porto. Email: jresende@fep.up.pt. This research has been financed by the European Regional Development Fund (ERDF) through the NORTE 2020 - Programa Operacional do Norte under the project NORTE-01-0145-FEDER-028540. This work has also been financed by CE-FUP through COMPETE 2020 - POCI and FCT in the framework of the project POCI-01-0145-FEDER006890 .
} 


\section{Introduction}

In recent years, the rapid growth of new-generation digital technologies has been reshaping firms' business models in many economic sectors, such as retail, energy, automobiles, fashion and apparels, media and entertainment, and so on. In particular, such technologies (including machine learning, robotics, digital platforms, 3D printing, etc.) enable firms to engage in innovative personalization strategies, through which they tailor their product/price offers to suit consumers' individual preferences and needs, which become known to the firms thanks to their collection and treatment of very large volumes of data about their customers.

Indeed, firms are now able to track consumers' purchase behavior much more easily, gathering and processing unprecedented amounts of real time data about their customers. The access to such "Big Data" on customers allows firms to: (i) get very accurate information and forecasts about consumers' behavior and preferences, overcoming possible asymmetric information issues; (ii) use hyper-segmented data on consumers to identify which products could fit better the consumers' preferences/needs and to assess individual consumers' willingness to pay for such products. ${ }^{1}$ Furthermore, new generation digital technologies (e.g. AI, 3-D printing ${ }^{2}$ and digital design platforms for product co-creation) are allowing firms to effectively deliver personalized product-price offers to their customers at scale. ${ }^{3}$

In this paper, we investigate the market dynamics that arise when

\footnotetext{
${ }^{1}$ As Zinsmeister (2016) puts it, "both prioritization and personalization are key when it comes to your hyper-segmentation strategy. Rather than creating a few rigid personas or a large list based on broad firmographic characteristics, hyper-segmentation allows you to use all of your customer data to pinpoint specific marketing problems you can solve for smaller customer groups, aka a 'segment of one."' https://martechtoday.com/achieving-hyper-segmentation-reachpersonalization-scale-165097 [Access date: 10/02/2019]

${ }^{2}$ According to the European Commission (2017), "In the future, 3D printing may impact the locations of plants. Given the ability to create highly customized products with fewer overheads and production steps, many companies perceive $3 D$ printing as an opportunity to re-shore manufacturing back to Western countries." https://ec.europa.eu/growth/toolsdatabases/dem/monitor/sites/default/files/DTM_The\%20disruptive\%20nature\%20 of\%203D\%20printing\%20v1.pdf [Access date: 10/02/2019]

${ }^{3}$ As reported in the New York Times (2018), "For some brands, a future of made-to-order everything is on its way to becoming a reality. Nike, for instance, is experimenting with new customization and personalization concepts in its stores, where consumers can help to create products, said John R. Hoke III, Nike's chief design officer." https://www.nytimes.com/2018/11/19/fashion/luxuryretail-personalization.html [Access date: 10/02/2019]
} 
a monopoly firm is able to collect Big Data about its customers (after their first purchase) in order to engage in hyper-segmentation strategies. To facilitate our investigation, we propose a dynamic extension of the static model of Mussa-Rosen (1978) on monopoly and product quality, in which we envisage consumers' repeated purchases of a non-durable good for instantaneous consumption. We assume that the monopolist cannot modify the price-quality schedules offered to its customers during an exogenous period of finite length (which corresponds to the usual contractual commitment period in dynamic models investigating the Coasian conjecture).

Each period, the monopolist proposes to new customers a periodspecific price-quality schedule intended to have them reveal their true type. Once a consumer makes her first purchase, the firm is able to collect "big data" to uncover the consumer's type. For example, in the context of digital markets, such information could be collected through cookies and other tracking devices that allow firms to recover the consumers' digital footprint. The process of collecting the necessary information to identify the consumers' specific features may obviously take some time. In our model, this is captured by the duration of the finitelength period in which the monopolist cannot change the price-quality offers made to new consumers. As soon as the firm uncovers the new consumers' specific preferences, it starts using a hyper-segmentation strategy, through which old customers receive a personalized product-price offer. In other words, the firm uses the information on the old consumers' tastes to tailor its quality/price offer. As a result, it upgrades its quality offer to the consumers who have bought the good for the first time in the previous period but it also increases the corresponding price, maximizing the consumers' surplus (which it fully extracts through the implementation of first-degree price discrimination).

Accordingly, in our set-up consumers can cheat and misreport their types only in the first period in which they purchase the good for the first time. In other words, only new consumers (who are buying the good for the first time) may earn information rents. Once the firm gets information on the consumer's type, in subsequent periods it will actually offer her a personalized product/price deal that fully expropriates any possible rent. Hence, the model combines second-degree discrimination with respect to new customers (whose preferences are unknown to the monopolist) with first-degree discrimination on former customers (whose preferences have become known to the monopolist). Consequently, the monopolist only needs to distort downward the quality offered to the successive rungs of the customers who buy the good for the first time. ${ }^{4}$

\footnotetext{
${ }^{4}$ If we were to assume the absence of tracking devices and big data collection,
} 
Our main focus is on the case where the monopolist is unable to commit to future sales decisions. Under this scenario, we characterize the Markov Perfect Equilibrium of the dynamic game played by the firm and its customers. The firm makes decisions on the quality-price schedules to be offered to new customers and personalized offers to old customers, whereas the targeted new consumers decide when to make their first purchase (anticipating that the firm will be able to collect Big Data on them as soon as they buy the product for the first time). In the Markov Perfect Equilibrium, the monopolist quality/price strategy maximizes its discounted lifetime profit, given consumers' expectations; and, given the monopolist's sales strategy, consumers' expectations are rational.

Due to the asymmetric information issues faced by the firm when it sells its product to consumers for the first time, the firm derives greater profits on old customers than on new ones. While the firm is able to extract the maximum surplus from old consumers, it is not able to do so with new consumers (whose preferences are unknown to the firm). In view of this, one might be tempted to conjecture that in the Markov Perfect Equilibrium the firm would want to expand its customer base as quickly as possible in order to get full information about all its customers in a twinkling of an eye. If that conjecture were correct, it would follow that, when the length of the contractual commitment period shrinks to zero, the whole market would be covered instantaneously, replicating the predictions of Coasian dynamics.

It turns out, however, that such market dynamics cannot actually arise in equilibrium, because the above conjecture is false: it neglects the role of consumers' participation constraint, which in effect restrains the speed of market expansion and acts, to a certain extent, as a mechanism to limit the firms' ability to get immediate full information about all the consumers in the market. The intuition is the following. Consider two successive rungs of new customers, who are offered different pricequality schedules such that only the top customers in each rung receive the undistorted first-best optimal quality. The other ones, including the marginal customers in each period, are offered sub-optimal quality levels (the distortion for bottom customers is greater, the bigger is the preference gap between the top and bottom new customers in each period, i.e. the quicker is the market expansion). Hence, if the marginal customers delay their purchase until the next period, they may receive a higher, possibly first-best, quality, which means that these consumers may be tempted to choose the delay strategy, especially when the wait is not

misreporting would impact the options offered to old consumers as well. In that case, the latter would also be offered distorted quality levels. 
too long. In order to entice consumers to participate, the firm needs to reduce customers' incentives to delay their purchase, which means that it must slow down the market expansion from one period to the next. (This "slowing down" motive is all the more powerful if the contractual commitment period is short).

Accordingly, concerning market expansion when the (exogenously specified) length of the commitment period tends to zero, there are two opposite effects at work: (i) each period is shorter, implying that the rate of arrival of a new cohort of first-time customers is faster, (ii) in response to the reduced length of the commitment period, the firm tends to reduce the size of each new cohort in order to accommodate the consumers' participation constraint. Hence, in equilibrium, the market is never covered "in a twinkling of an eye" but only progressively. In this respect, it is interesting to notice that, under the Markov perfect equilibrium, our results depart substantially from the standard MussaRosen outcomes. While in their case, some consumers are left out of the market, in our case, regardless of the length of the commitment period (as long as it is not infinite), the market ends up being fully covered (at least asymptotically).

Another interesting finding is that the monopolist's equilibrium profit increase when the length of the period of commitment decreases. The underlying reason is quite intuitive: the shorter the period of commitment, the more quickly the firm may exercise first-degree price discrimination, extracting all former customers' surpluses. In fact, looking at the set of successive new consumers only, the length of the commitment period can also be interpreted as the time the firm needs to collect full information on the profile of its new customers (which enables it to implement hypersegmented price/quality offers). Hence, it does not come as a surprise that in our model, the monopolist's profit increases when the length of the commitment period decreases. Thus, one important contribution of our work is to show that the non-Coasian dynamics are the logical outcome of the combination of consumers' recognition through "big data" and the use of price-quality schedules as screening devices for successive sets of new customers.

Contrary to the firm, consumers as a whole are hurt by the shortening of the contractual commitment period (as it is translated into a reduction in the length of the time period that the firm needs in order to get a fully accurate profile for its new consumers). Here, again, this is quite intuitive: consumers derive a positive surplus from their purchases only when they enter the market. So, the longer is the firm's commitment period in which they actually remain new customers, the greater is their intertemporal utility. 
The consumers and the monopolist's interests being thus diametrically opposed, it is interesting to see what could be in this framework a socially optimal regulatory policy: would it be welfare-improving to impose a minimum length of contractual commitment? We indeed show that social surplus is non-monotonic, attaining its maximum at a strictly positive but finite value of the length of the contractual commitment period. Hence, our model provides one possible theoretical justification for the adoption of regulatory policies such as the General Data Protection Regulation in the European Union. By limiting firms' ability to collect information on consumers, this type of policies ends up resulting in an increase of the length of the contractual commitment period.

Finally, we compare the baseline model to a theoretical benchmark in which the monopolist would be able to commit from the beginning to a sequence of pre-determined contracts, both for new and former customers, dependent on the period of their first purchase. We find that the difference with the non-commitment case regards only new customers, to which a time-invariant contract is proposed, independently of the date of their initial purchase. Old customers are offered, as in the non-commitment case, a contract in which they receive their first-best optimal quality at a price which leaves them with no surplus. In the case of new customers, we obtain the results that (i) the higher a new consumer's type is, the higher the quality she is offered, and (ii) there is a cut-off type, below which low-preference consumers are not served. Clearly, in the commitment case the outcomes for new customers replicate the equilibrium quality/price schedule of the static Mussa-Rosen model. However, the commitment equilibrium is not time-consistent.

The rest of the paper is organized as follows. Section 2 presents a brief overview of the literature. Section 3 describes the main ingredients of the model. Section 4 investigates the dynamic game played by the monopolist and its consumers when the former is unable to commit to future sales contracts, characterizing the Markov Perfect Equilibrium of the underlying game. Section 5 analyzes how equilibrium outcomes would change if the monopolist were able to commit to a sequence of pre-determined contracts. Section 6 analyzes the welfare implications of our model and, finally, Section 7 concludes.

\section{Related literature}

In recent years, the analysis of firms' (price) personalization based on consumer recognition has attracted a great attention both in the fields of economics and management science. A recent literature has dealt with the effects of endogenous acquisition of information about consumers 
through the analysis of their purchase history ${ }^{5}$ in multi-period (typically two-period) models. This is what is known as "behavior-based price discrimination" (for a survey see Fudenberg and Viallas-Boas (2006)). Fudenberg and Tirole (2000), for instance, focused on the simple case of a two-period duopoly model with horizontal product differentiation. ${ }^{6}$ In the second period, firms are able to engage in third-degree price discrimination between old and new customers (depending on whether these consumers belong to the firm's own turf or to the rival's one). Rhee and Thomadsen (2017) and Jing (2017) conducted an analogous analysis in two-period vertical differentiation duopoly models. In these models, all that is required for second-period price discrimination is that firms recognize in the second period their former customers and distinguish them from their rival's. More recent papers (see for instance Choe, King and Matsushima, 2017, or Laussel and Resende, 2019) have gone further by assuming that tracking devices and big data allow the firms not only to know if a given customer is (or is not) a former customer but also to identify the consumers' exact preferences (i.e., their location on the Hotelling line).

When targetability is imperfect, the literature has pointed out that firms may actually benefit from price discrimination based on customer recognition. Indeed, first degree price discrimination is not possible when information about customers is imperfect. In such cases, Chen, Narasimhan and Zhang (2001, p. 25) show that individual marketing with imperfect targetability can lead to a win-win outcome if firms exchange with each other information about their customers. ${ }^{7}$

The present paper also focuses on how firms' price (and product specification) strategies may be reshaped by using this kind of tracking devices/big data. We depart from previous literature by looking at price discrimination through customer recognition in a fully dynamic set-up in which a monopoly makes hyper-segmented quality specification offers to its customers (whereas the previous literature on this issue is exclusively based on static oligopoly models or on two-period oligopoly models).

\footnotetext{
${ }^{5}$ For the conditioning of prices on purchase history see for instance Acquisti and Varian (2005), Chen (2005) or Chen and Iyer (2002).

${ }^{6}$ Villas-Boas (1999) extended this model to an infinite-horizon, overlapping generation model, where each firm cannot distinguish between new-generation customers and its rival's first-period customers.

${ }^{7}$ The reason why imperfect targetability may lead to a win-win outcome in Chen et al. (2001) is that their model allows for misperception. They wrote that "due to imperfect targetability, each firm mistakenly perceives some price-sensitive switchers as price-insensitive loyal customers and charge them all a high price. These misperceptions thus allow its competitors to acquire those mistargeted customers without lowering their prices and hence, reduces the rival firm's incentive to cut prices. This effect softens price competition" (p. 23).
} 
In building our model, we draw from two distinct streams of literature. The first stream addresses the issue of the losses that arise from a monopolist's inability to commit, and this does not need to have anything to do with the issue of revelation of private information. The second stream deals with private information issues and the resulting informational rents: consumers are heterogeneous in terms of their individual values of a preference parameter, which are private information until the moment they make their first purchase.

By combining these two streams of literature, we are able to derive novel results concerning the market dynamics and consumers' informational rents, highlighting firms' incentives to offer personalized qualityprice schedules to successively new sets of customers. Indeed, pricequality offers vary not only across individuals (depending on their typespecific taste parameter) but they may also differ from one period to the next for a given individual. In particular, after their first purchases at a constant price over a short period of commitment, in subsequent periods individuals are offered a quality upgrade, the benefits of which are fully expropriated by the firm, as they have to pay a high price for this product.

The first stream of literature mentioned above has its origin from Coase (1972). Assuming that consumers have rational expectations, Coase (1972) argued that, in continuous time, if a monopolist selling a durable good is not able to make commitment about its future prices and outputs, it will lose all its monopoly power: in equilibrium, the price must be equal to the constant marginal cost, and the monopolist must serve all its customers immediately in one go. This conjecture has been subsequently proved rigorously. In particular, using a model with heterogeneous valuations where each consumer buys at most one unit, Bulow (1982) confirms this result for the "No Gap" case, defined as the situation in which the constant marginal cost is higher than the willingness to pay for the good of the (unserved) consumer with the lowest valuation. There are a number of exceptions (see, e.g. Kahn, 1987, for non-constant marginal cost, and Karp, 1996, for durable goods subject to depreciation). Of particular interest is the case where the durable good is subject to network externalities, for then the Coase conjecture may fail (e.g. Mason, 2000; Laussel, Long, and Resende, 2015). ${ }^{8}$ In the context of non-renewable resource markets, various authors have shown that the lack of ability to commit may reduce monopoly profit, or make monopoly power disadvantageous (Kemp and Long, 1980; Maskin and

\footnotetext{
${ }^{8}$ Laussel, Long, and Resende (2015) show that the standard results for Coasian dynamics must be modified when the durable-good monopolist participates in two distinct markets with network effects (the primary market and the aftermarket).
} 
Newbery, 1990). Similarly, the macroeconomic literature is abound with the disadvantages of governmental "discretion" as compared to "rule" (Kydland and Prescott, 1977).

The second stream of literature, which deals with informational rents when there is a continuum of types, arguably received the greatest impetus from Mirrlees (1971), who analyzed optimal income tax under asymmetric information. This was followed by a formal analysis of the revelation principle (e.g., Holmstrom, 1977, Myerson, 1979). This principle has been applied to models of regulation (Laffont and Tirole, 1986) and of incentive contracts (see, for example, Laffont and Tirole, 1988, Laffont and Martimor, 2002). The theory has been extended to the multi-dimensional case (e.g., Martimort, 2006), as well as the multiperiod case (e.g., the extension of Mirrlees' model to a multi-period setting, as in Kocherlakota, 2005; Golosov et al., 2003, 2016; Stantcheva, 2017).

Our paper is also related to the literature on Markov-perfect equilibrium in games involving firms with market power that interact with infinitely-lived consumers who have Markovian rational expectations (see, e.g., Driskill and McCafferty, 2001; Laussel, Montmarin and Long, 2004). For a recent survey of this literature, see Long (2015).

Finally, this paper highlights the role of the length of the period of commitment between any two different contract offers. We assume the firm can make commitment over a short time interval, and then we take the limit as the time interval goes to zero. This modelling feature is related to the earlier literature on the length of commitment period (Reinganum and Stokey, 1985; Bond and Samuelson, 1987; Mason, 2000).

\section{The Model}

A monopolist produces a non-durable product, whose quality level is denoted by $q$. The set of feasible quality levels belonging to the real interval $\left[0, q_{\max }\right]$ where 0 is the lowest quality, and $q_{\max }$ is the highest feasible quality. The unit cost depends on the quality level, and is denoted by $c(q)$.

Assumption A1: $c(0)=0, c^{\prime}(q) \geq 0, c^{\prime}(0)=0$, and $c^{\prime \prime}(q)>0$ for all $q>0$.

There is a continuum of consumer types. Let $\theta$ be a variable denoting the type of a consumer. Assume that $\theta$ is distributed over a closed interval $[\underline{\theta}, \bar{\theta}]$, where $\bar{\theta}>\underline{\theta} \geq 0$. The density function and the cumulative distribution function are denoted by $f(\theta)$ and $F(\theta)$ respectively, where $F(\underline{\theta})=0, \lim _{\theta \rightarrow \bar{\theta}} F(\theta)=1$, and $F^{\prime}(\theta)>0$ for all $\theta \in(\underline{\theta}, \bar{\theta})$. Let $h(\theta)$ 
denote the inverse hazard rate, $h(\theta)=\frac{1-F(\theta)}{f(\theta)}$.

Assumption A2: $h^{\prime}(\theta)<0$.

Assumption A2 is a standard assumption to ensure that there is no bunching in a second-degree discrimination model. This assumption is satisfied by many familiar distributions, such as the uniform, exponential, normal, binomial, and Poisson distributions. ${ }^{9}$

Assumption A3: $h(\underline{\theta})>\underline{\theta}$.

For the uniform distribution case, A3 is equivalent to $2 \underline{\theta}<\bar{\theta}$. Taken together, Assumptions A2 and A3 ensure that, in a static second-degree discrimination framework, the market is not covered. More precisely, there must exist a cut-off type $\theta^{c}>\underline{\theta}$, defined by $\theta^{c}-h\left(\theta^{c}\right)=0$ such that all types $\theta$ in the interval $\left[\underline{\theta}, \theta^{c}\right]$ are not served by the firm.

Herein, we investigate the monopolist's optimal quality-price decisions within an infinite horizon framework with customer recognition. Time is a continuous variable, $t \in[0, \infty)$ and a consumer at each time $t$ buys either one or zero unit of the good. Consumers live forever and the good is non-durable: it is consumed instantaneously, yielding the individual a net instantaneous utility

$$
u\left(q_{t}(\theta), p_{t}(\theta), \theta\right)=\theta q_{t}(\theta)-p_{t}(\theta)
$$

We refer to $\theta$ as the individual's marginal valuation of quality. Each individual's type is constant over time. ${ }^{10}$ The consumer's type is initially unknown to the firm. However, as soon as a consumer makes her first purchase, the firm can use tracking devices (e.g. cookies in the case of online shoppers, or fidelity cards in the case of more conventional brick-andmortar stores) to collect data about the consumers. Such data can then be treated by powerful algorithms to uncover the relevant information for the monopolist to accurately identify the consumers' type.

Assumption A4: $c\left(q_{\max }\right)>\bar{\theta} q_{\max }$.

Assumption A4 implies the firm would never produce the good at quality level $q_{\max }$, because the unit cost $c\left(q_{\max }\right)$ is higher than the highesttype consumer's maximum willingness to pay for a unit of the good at that quality level.

\footnotetext{
${ }^{9}$ For the uniform distribution, $F(\theta)=(\theta-\underline{\theta}) /(\bar{\theta}-\underline{\theta})$ and $h(\theta)=\bar{\theta}-\theta$.

${ }^{10}$ In our model, goods sold to customers who have the same $\theta$ have the same characteristics. In reality, customers who have the same valuation of quality may have different personal tastes (e.g., concerning design, as in clothes). Extending the model to account for such differences and for the cost of quality personalization would be an interesting topic of research.
} 
To the assumption that consumption takes place instantaneously, we add the assumption that the monopolist cannot modify the price-quality schedules offered to its customers during a period whose (finite) length $\Delta$ is exogenous in the model. ${ }^{11}$ There is an infinite sequence of periods, indexed by $n$, where $n=0,1,2,3, \ldots$ The first period (denoted by $n=0)$ corresponds to the subset $[0, \Delta)$ of the time line. The second period $(n=1)$ corresponds to the subset $[\Delta, 2 \Delta)$, and so on. At the beginning of each period $n$, the monopolist offers to all potential new customers (those who have not bought the good in some earlier period) a price-quality schedule, which applies for all points of time in the interval $[n \Delta,(n+1) \Delta)$

$$
p_{n}=\phi_{n}(q) \text {. }
$$

where $\phi_{n}$ is a mapping from the quality domain $\left[0, q_{\text {max }}\right]$ to the space of non-negative prices, $\mathbb{R}_{+}^{2}=[0, \infty)$. During each period (whose length $\Delta$ is the time that elapses between two different contract offers) the price and quality selected by a consumer at the beginning of the period are contractually fixed. If we focus on the cohorts of new consumers, an alternative interpretation for $\Delta$ is the length of time it takes to the firm to collect and process the information about the consumers' tastes in order to get accurate information on the new consumers' type (and then start implementing personalized quality-price offers).

We assume positive discounting, such that within each period, a dollar paid at the end of the period is worth only as much as a fraction $e^{-r \Delta}$ of a dollar paid at the beginning of the period, where $r>0$ denotes the instantaneous discount rate (which is constant and independent of $\Delta$ ). The same discounting applies to utility. Then a consumer of type $\theta$ who selects the quality $q_{n}(\theta)$ in period $n$ and pays the price $p_{n}(\theta) \equiv \phi_{n}\left(q_{n}(\theta)\right)$ at each $t \in[n \Delta,(n+1) \Delta)$ achieves the following net utility (properly discounted) for the period: ${ }^{12}$

$$
\begin{aligned}
v_{n}(\theta) & \equiv \int_{0}^{\Delta} u\left(p_{n}(\theta), q_{n}(\theta), \theta\right) e^{-r \tau} d \tau=\left[\theta q_{n}(\theta)-p_{n}(\theta)\right] \int_{0}^{\Delta} e^{-r \tau} d \tau \\
& =\frac{\left[\theta q_{n}(\theta)-p_{n}(\theta)\right]}{r}\left(1-e^{-r \Delta}\right) \equiv\left[\theta q_{n}(\theta)-p_{n}(\theta)\right] \frac{1-\beta}{r}
\end{aligned}
$$

Note that $r$ is independent of $\Delta$, whereas $\beta$ is the discount factor between periods, $\beta \equiv e^{-r \Delta}$. Clearly $\beta \rightarrow 1$ when $\Delta \rightarrow 0$.

\footnotetext{
${ }^{11}$ One may imagine that there is a minimum length which allows the firm to collect the data necessary to discover the customers' types, but here $\Delta$ is contractual and may well exceed this minimum length.

${ }^{12}$ Defining $\theta q-p$ as the utility over period $n$ would have the undesirable consequence that the utility per unit of time would increase when the length $\Delta$ of the period would decrease, tending to $\infty$ as $\Delta$ tends to 0 .
} 
At the beginning of any period $n(n=0,1,2, \ldots)$, the firm faces two disjoint subsets of customers: those whose type belongs to $\left(\theta_{n}, \bar{\theta}\right]$ are customers who have already bought the good in some previous periods (and therefore the monopolist is fully informed about their preferences) and those whose types belong to $\left[\underline{\theta}, \theta_{n}\right]$ have never purchased it (and therefore they are potentially new consumers, whose preferences remain unknown to the firm). Among the latter, the consumers whose types $\theta$ belong to $\left(\theta_{n+1}, \theta_{n}\right]$, with $\theta_{n+1}<\theta_{n}$ will be induced to buy the good for the first time in period $n$ (each type at a different quality level, according to their own $\theta$, as there is no bunching under our assumptions). Accordingly, type $\theta_{n+1}$ consumers are called the marginal consumers in period $n$. In equilibrium they are indifferent between (a) being a firsttime consumer in period $n$, at the bottom of the rung, and (b) being a first-time consumer in period $n+1$, at the top of the rung. ${ }^{13}$ It is not difficult to show that in equilibrium (i) if a type- $\theta$ consumer has already bought the good, so have all type- $\theta^{\prime}$ customers such that $\theta^{\prime}>\theta$, and that (ii) if a type- $\theta$ consumer has not purchased the good, all type- $\theta^{\prime}$ customers such that $\theta^{\prime}<\theta$ also have not done so. We assume that initially nobody has purchased the good, i.e., $\theta_{0}=\bar{\theta}$.

In the following section, we will look at the monopolist's optimal price-quality decisions in a dynamic set-up in which the monopolist is able to fully track consumers' tastes after their first purchase (and uses this information to implement price/quality discrimination based on consumer recognition). In the next section, we consider the case where the monopolist cannot commit to future contract offers. Afterwards, we will compare equilibrium outcomes described in the next section to the ones arising in a model where the monopolist fully commit to a sequence of price/quality offers.

\section{Equilibrium under non-commitment}

The monopolist's inability to commit to future prices and qualities has two aspects. First, when selling to first-time consumers in period $n$, the firm cannot commit to offer them in periods $n+j$ (where $j=1,2,3 \ldots$ ) the same contract as the initial one when they come back to purchase the good. More generally, in any period $n$, the monopolist cannot commit to offer pre-determined contracts to new customers in periods $n+j$, $j=1,2,3 .$. , even though such offers could profitably induce potential

\footnotetext{
${ }^{13}$ This implies that they obtain a higher surplus per unit consumed in period $n+1$ (if they choose to be first-time consumers in period $n+1$ ) than the surplus per unit consumed in period $n$ (if they choose to be first-time consumers in period $n$ ), but this difference is fully offset by the fact that the surplus is delayed by $\Delta$ units of time. See eq. (12) below.
} 
first-time consumers in period $n$ to purchase in that period, in preference to delaying their purchase until the next period or later periods.

On the other hand, due to 'big data' collection by the firm, customers' type has become known after their first purchase so that the monopolist always uses first-degree discrimination with respect to old customers (hence, even if the monopolist could commit to future contracts, it does not have any incentive to distort the quality offered to former customers).

Let us study the implications of these considerations.

\subsection{Old customers: quality and price personaliza- tion}

Contrary to the one-shot problem studied by Mussa and Rosen (1978), a consumer does not purchase the good only once. At the beginning

of period $n$, all consumers whose types belong to $\left(\theta_{n}, \bar{\theta}\right]$ have already purchased the good at least once in previous periods. Because the firm maintains a data base of former customers, when they come back in subsequent periods it will not offer them contracts designed for new customers. Instead, it will make them personalized offers, extracting all their consumer's surplus $\theta q-c(q)$. Thus, the firm exclusively offers to a type- $\theta$ former customer a good with quality level $q^{*}(\theta)$ which equates the consumer's marginal valuation of quality, $\theta$, with the marginal cost of quality upgrading,

$$
\theta-c^{\prime}\left(q^{*}(\theta)\right)=0 .
$$

and charges the corresponding surplus-eliminating price $p^{*}(\theta)=\theta q^{*}(\theta)$.

Under Assumption A1, $q^{*}(\theta)$ is uniquely defined by (1). Since $c^{\prime}(0) \leq$ $\underline{\theta}$, it is clear that in any period $n$ the monopolist earns a positive profit from each former customer of type $\theta$ by making the take-it-or-leave-it offer $\left(q^{*}(\theta), \theta q^{*}(\theta)\right)$.

Let us denote by $\pi^{F}(\theta)$ the profit thus obtained from a sale to a former customer of type $\theta$

$$
\pi^{F}(\theta) \equiv \theta q^{*}(\theta)-c\left(q^{*}(\theta)\right) .
$$

The aggregate profit earned in period $n$ from selling to all former customers (those whose types are in the interval $\left.\left(\theta_{n}, \bar{\theta}\right]\right)$ is then given by

$$
\Pi_{n}^{F}=\frac{1-\beta}{r} \int_{\theta_{n}}^{\bar{\theta}} \pi^{F}(\theta) f(\theta) d \theta,
$$

where the superscript $F$ stands for "former" customers. 


\subsection{New customers: screening mechanism}

The monopolist is uncertain about the type of consumers who haven't bought the good yet. Thus, in order to discriminate among new customers, the monopolist uses a screening mechanism. At the beginning of period $n$, the targeted new customers are those whose type $\theta$ belongs to the interval $\left(\theta_{n+1}, \theta_{n}\right]$. We will refer to members of this group as vintage- $n$ customers. By offering a price-quality schedule $p_{n}(q)$ for these first-time consumers ${ }^{14}$, it is indeed possible to induce them to select a couple $\left(q_{n}(\theta), p_{n}(\theta)\right)$, provided that an incentive compatibility condition (ICC) is satisfied. The nature of the ICC is explained below.

Being rational, these first-time consumers fully expect that the monopolist, in later periods, will offer them a take-it-or-leave-it offer that extracts all their surplus. The consumer knows that the firm will gather data about her tastes, identifying her true type after her first purchase. Hence, any consumer who has reported a type $\widehat{\theta}$ (regardless of whether it is equal to her true $\theta$ or not) knows that, in all subsequent periods, she will be proposed a quality $q^{*}(\theta)$ as defined by (1) and a price $\theta q^{*}(\theta)$ such that the surplus of the reported consumer is fully extracted by the monopolist.

Truthful reporting is optimal for a type $\theta$-customer (when she purchases the good for the first time, say in period $n$ ) if and only if pretending to be a different type (say $\widehat{\theta} \neq \theta$ ) would make her worse off than telling the truth:

$$
\frac{1-\beta}{r}\left(\theta q_{n}(\theta)-p_{n}(\theta)\right) \geq \frac{1-\beta}{r}\left(\theta q_{n}(\widehat{\theta})-p_{n}(\widehat{\theta})\right)
$$

where the right-hand side (RHS) term is the net utility earned in period $n$ by misreporting one's type (pretending to be of type $\widehat{\theta}$ instead of type $\theta$ ). The left-hand side (LHS) is the net utility earned in period $n$ if the consumer is truthful. The above ICC condition may be written as

$$
\theta=\arg \max _{\widehat{\theta}} \frac{1-\beta}{r}\left(\theta q_{n}(\widehat{\theta})-p_{n}(\widehat{\theta})\right) .
$$

Let us denote the net utility of a first-time buyer of type $\theta \in\left[\theta_{n+1}, \theta_{n}\right]$ in period $n$ by

$$
U_{n}(\theta) \equiv \max _{\widehat{\theta}} \frac{1-\beta}{r}\left(\theta q_{n}(\widehat{\theta})-p_{n}(\widehat{\theta})\right) .
$$

\footnotetext{
${ }^{14} \mathrm{Or}$, equivalently, a direct mechanism $(q(\widehat{\theta}), p(\widehat{\theta}))$ depending on the type $\widehat{\theta}$ which the consumer chooses to report.
} 
The envelope theorem implies that the pair $\left(q_{n}(\theta), p_{n}(\theta)\right)$ is incentive compatible iff

$$
U_{n}^{\prime}(\theta)=\frac{1-\beta}{r} q_{n}(\theta)
$$

Accordingly, by integrating (6), we find that for all $\theta \in\left[\theta_{n+1}, \theta_{n}\right]$, it holds that

$$
U_{n}(\theta)=U_{n}\left(\theta_{n+1}\right)+\int_{\theta_{n+1}}^{\theta}\left(\frac{1-\beta}{r} q_{n}(s)\right) d s,
$$

where the integral on the RHS is the difference between the informational rent of a type- $\theta$ consumer, where $\theta_{n+1} \leq \theta \leq \theta_{n}$, over the informational rent of a marginal type $\theta_{n+1}$, who is indifferent between (a) being firsttime customer in period $n$, at the bottom of the rung, and (b) being first-time customer in period $n+1$, at the top of the rung. For later use, let us denote by $R\left(\theta_{n}, \theta_{n+1}\right)$ the difference between the informational rent of first-time customer at the top rung in period $n$ and that of the first-time customer at the bottom rung in period $n$ :

$$
R\left(\theta_{n}, \theta_{n+1}\right) \equiv \int_{\theta_{n+1}}^{\theta_{n}} \frac{1-\beta}{r} q_{n}(s) d s .
$$

Equation (5) gives:

$$
U_{n}(\theta)=\frac{1-\beta}{r}\left(\theta q_{n}(\theta)-p_{n}(\theta)\right) .
$$

Moreover, a familiar revealed preference argument yields the following inequality (second incentive-compatibility constraint):

$$
\frac{1-\beta}{r} q_{n}^{\prime}(\theta) \geq 0
$$

This implies, via $(6)$, that $U_{n}(\theta)$ is convex in $\theta$.

A pair $\left(q_{n}(\theta), p_{n}(\theta)\right)$ is incentive-feasible if, in addition to the incentive compatibility condition (6) (or, equivalently, (7)), it also satisfies the following participation constraint (PC) for first-time buyers in period $n$ :

$$
U_{n}(\theta)-\beta\left[\frac{1-\beta}{r}\left(\theta q_{n+1}^{b}(\theta)-p_{n+1}^{b}(\theta)\right)\right] \geq 0, \forall \theta \in\left[\theta_{n+1}, \theta_{n}\right]
$$

where $\left(q_{n+1}^{b}(\theta), p_{n+1}^{b}(\theta)\right)$ denote the best price-quality pair that a type- $\theta$ consumer would choose in period $n+1$ if she delays her first purchase to period $n+1$. 
To understand the PC (11), note that a type $\theta$-consumer, where $\theta \in$ $\left[\theta_{n+1}, \theta_{n}\right]$, that the monopolist targets as a potential first-time customer in period $n$ can deviate by delaying her first purchase to the next period. The firm, wishing to prevent such a deviation, must ensure that her net utility from buying as a first-time customer in period $n$ is greater than or equal to her net utility from buying as a first-time customer in period $n+1$. Since the monopolist is able to identify the true type of all those customers who have made their first purchase and will extract their whole surplus in subsequent periods, the life-time net utility of a firsttime customer in period $n$ is simply equal to the net utility obtained in period $n$ itself (the net utility from her purchases in periods $i>n$ being zero). The (discounted) life-time net utility obtained by a consumer of type $\theta \in\left[\theta_{n+1}, \theta_{n}\right]$ who delays her first purchase to period $n+1$ is

$$
\beta\left[\frac{1-\beta}{r}\left(\theta q_{n+1}^{b}(\theta)-p_{n+1}^{b}(\theta)\right)\right] .
$$

Hence, such type- $\theta$ consumer will choose to buy in period $n$ iff $U_{n}(\theta) \geq$ $\beta\left[\frac{1-\beta}{r}\left(\theta q_{n+1}^{b}(\theta)-p_{n+1}^{b}(\theta)\right)\right]$. The RHS of this inequality is the reservationutility level of the targeted type- $\theta$ consumer. It turns out that this reservation level can be easily characterized, this is the essence of Claim 1 below.

Claim 1. A type- $\theta$ customer, where $\theta \in\left[\theta_{n+1}, \theta_{n}\right]$, when evaluating the merit of delaying her first-time purchase to period $n+1$ instead of buying in period $n$, will find it optimal (conditional on deviating) to report the highest type among consumers who buy in period $n+1$, i.e., $\widehat{\theta}=\theta_{n+1}$.

Proof. See the Appendix.

Given Claim 1, the participation constraint (11) for any type $\theta \in$ $\left[\theta_{n+1}, \theta_{n}\right]$ may be written as

$$
\Delta_{n}(\theta) \equiv U_{n}(\theta)-\beta\left(\frac{1-\beta}{r}\left(\theta q_{n+1}\left(\theta_{n+1}\right)-p_{n+1}\left(\theta_{n+1}\right)\right)\right) \geq 0
$$

i.e., the price-quality schedule offered to new customers in period $n$ and the schedule offered to new customers in period $n+1$ must be such that, for all $\theta \in\left[\theta_{n+1}, \theta_{n}\right]$, buying for the first time in period $n$ is at least as advantageous as doing so in period $n+1$.

Since $\theta_{n+1}$ is defined as the marginal type who is indifferent between buying for the first time at $n$ and buying at $n+1$, it holds that, condition 
(12), when evaluated at $\theta=\theta_{n+1}$, is satisfied with equality, i.e., we have $\Delta_{n}\left(\theta_{n+1}\right)=0$. How can we ensure that the participation constraint (12) is satisfied also for all the inframarginal types, $\theta>\theta_{n+1}$ ? Lemma 1 below provides a necessary and sufficient condition.

Lemma 1. The participation constraint (12) is satisfied for all $\theta \in$ $\left[\theta_{n+1}, \theta_{n}\right]$ iff, in addition to the condition that the marginal first-time customer is indifferent, i.e., $\Delta_{n}\left(\theta_{n+1}\right)=0$, the following inequality is met

$$
q_{n}\left(\theta_{n+1}\right)-\beta q_{n+1}\left(\theta_{n+1}\right) \geq 0
$$

Proof. See the Appendix.

Condition (13) requires that the lowest quality offered to new customers in period $n$ is greater than the (discounted) highest quality offered to new customers in period $n+1$.

Recall that $q_{n+1}\left(\theta_{n+1}\right)$ is the quality level intended for the highest consumer type among those who purchase for the first time in period $n+1$. One may expect that the familiar property (that holds in the static setting) that there is "no distortion at the top" also applies in our dynamic model, so that $q_{n+1}\left(\theta_{n+1}\right)=q^{*}\left(\theta_{n+1}\right)$, which turns out to be the case in equilibrium, as it will be verified afterwards. When this is indeed the case, constraint (13) reduces to:

$$
q_{n}\left(\theta_{n+1}\right) \geq \beta q^{*}\left(\theta_{n+1}\right) .
$$

that is, the quality offered to the lowest-type first-time customer in period $n$ is greater than the (discounted) first-best quality for that type. Recalling that in static second-degree discrimination settings, the monopolist distorts the quality level offered to low-type customers while offering the first-best optimal one to the highest type, one would expect that the marginal type $\theta_{n+1}$ is likely to be offered a lower quality when consuming in period $n$ than when she delays her purchase in period $n+1$. Constraint (13) is accordingly more difficult to satisfy for large values of $\beta$ (i.e., for small values of $\Delta$ ). We shall see that this will force the monopolist to slow down the expansion of the market in order to reduce the ratio $q^{*}\left(\theta_{n+1}\right) / q_{n}\left(\theta_{n+1}\right)$.

This participation constraint will play a key role in explaining the dynamics that arise in our model. Indeed, as shown in the next subsection, the constraint (14) binds at a Markov Perfect Equilibrium, slowing down market coverage and specifically ruling out any Coasian dynamics in which the market would be covered "in a twinkling of an eye." 
Finally, from (9) and (11), the condition $\Delta_{n}\left(\theta_{n+1}\right)=0$ implies that

$$
U_{n}\left(\theta_{n+1}\right)=\beta U_{n+1}\left(\theta_{n+1}\right) .
$$

Equation (15) indicates that marginal consumers in period $n$ are indifferent between being the lowest type among all new consumers in period $n$ and being the highest type among all new consumers in period $n+1$ (the higher surplus being exactly offset by the discount factor). With the help of equation (7) evaluated at $n+1$, this indifference condition implies the following dynamic relationship between the net utilities obtained by the marginal first-time customers in period $n$ and period $n+1$ :

$$
U_{n}\left(\theta_{n+1}\right)=\beta\left(U_{n+1}\left(\theta_{n+2}\right)+\int_{\theta_{n+2}}^{\theta_{n+1}}\left[\frac{1-\beta}{r} q_{n+1}(\theta)\right] d \theta\right) .
$$

Using (16) and (8), we deduce that

$$
\begin{aligned}
U_{n}\left(\theta_{n+1}\right) & =\sum_{j=1}^{\infty} \beta^{j}\left(\int_{\theta_{n+j+1}}^{\theta_{n+j}}\left[\frac{1-\beta}{r} q_{n+j}(\theta)\right] d \theta\right) \\
& =\sum_{j=1}^{\infty} \beta^{j} R\left(\theta_{n+j}, \theta_{n+j+1}\right) .
\end{aligned}
$$

Recall that $U_{n}\left(\theta_{n+1}\right)$ is the rent of the marginal new customer in period $n$. The above equation shows that, in equilibrium, such rent must be equal to the discounted sum (over $j$ ) of the differences between the informational rent of the top first-time customer and that of the bottom first-time customer in period $n+j$.

In period $n$, the monopolist's profit from sales to new customers, $\Pi_{n}^{N}$, is therefore equal to

$$
\Pi_{n}^{N}=\frac{1-\beta}{r} \int_{\theta_{n+1}}^{\theta_{n}}\left[p_{n}(\theta)-c\left(q_{n}(\theta)\right)\right] f(\theta) d \theta
$$

where the superscript $N$ in $\Pi_{n}^{N}$ stands for "new customers."

Re-arranging terms, we get

$$
\Pi_{n}^{N}=\frac{1-\beta}{r} \int_{\theta_{n+1}}^{\theta_{n}}\left\{\left[\theta q_{n}(\theta)-c\left(q_{n}(\theta)\right)\right]-\left[\theta q_{n}(\theta)-p_{n}(\theta)\right]\right\} f(\theta) d \theta .
$$

Using equation (9), we can rewrite (20) as

$$
\Pi_{n}^{N}=\int_{\theta_{n+1}}^{\theta_{n}}\left[\left(\frac{1-\beta}{r}\right)\left(\theta q_{n}(\theta)-c\left(q_{n}(\theta)\right)-U_{n}(\theta)\right] f(\theta) d \theta .\right.
$$


Equation (21) shows that the profits obtained from sales to new customers in period $n$ is equal to the "vintage $n$ total virtual surplus" (i.e., gross utility minus production cost minus the life-time rent of all firsttime consumers of vintage $n$ ).

It is shown in the Appendix that the RHS of equation (21) is equivalent to

$\int_{\theta_{n+1}}^{\theta_{n}} \frac{1-\beta}{r}\left[\theta q_{n}(\theta)-c\left(q_{n}(\theta)\right)-\frac{F\left(\theta_{n}\right)-F(\theta)}{f(\theta)} q_{n}(\theta)-U_{n}\left(\theta_{n+1}\right)\right] f(\theta) d \theta$.

Let $q_{n}^{N}(\theta)$ denote the quality level that maximizes the term inside the square brackets [...] in eq. (22). Then $q_{n}^{N}(\theta)$ is uniquely determined by the condition

$$
\theta-\left(\frac{F\left(\theta_{n}\right)-F(\theta)}{f(\theta)}\right)-c^{\prime}\left(q_{n}^{N}(\theta)\right)=0, \text { for all } \theta \in\left[\theta_{n+1}, \theta_{n}\right]
$$

Since $F\left(\theta_{n}\right)-F(\theta)>0$ for all $\theta>\theta_{n}$, condition (23) implies that there is quality distortion for all first-time customers except for type $\theta_{n}$. This confirms that the familiar property called "no-distortion at the top" in static models also applies to each group of new customers in our dynamic model.

Remark: Given Assumptions A1 and A2, we can prove that $q_{n}^{N}(\theta)$ is a strictly increasing function of $\theta$ provided that

$$
f^{\prime}(\theta) / f(\theta) \leq f(\theta) /\left[1-F\left(\theta_{n}\right)\right]
$$

The latter condition ensures that higher-type consumers are offered strictly higher quality levels. To see this, rewrite (23) as

$$
\theta-h(\theta)+\frac{\left[1-F\left(\theta_{n}\right)\right]}{f(\theta)}=c^{\prime}\left(q_{n}^{N}(\theta)\right)
$$

Then

$$
1-h^{\prime}(\theta)-\frac{\left[1-F\left(\theta_{n}\right)\right] f^{\prime}(\theta)}{(f(\theta))^{2}}=c^{\prime \prime}\left(q_{n}^{N}(\theta)\right) \frac{d q_{n}^{N}(\theta)}{d \theta},
$$

where $-h^{\prime}(\theta) \geq 0$, given Assumption A2. It follows that $\frac{d q^{N}(\theta)}{d \theta}>0$ provided that $f^{\prime}(\theta) / f(\theta) \leq f(\theta) /\left[1-F\left(\theta_{n}\right)\right]$. 


\subsection{The Markov Perfect Equilibrium}

In this subsection we focus on Markov Perfect Equilibria (MPE for short). In a MPE, the strategy of the monopolist is expressed as function of a state variable, say $\Theta(n)$ (to be defined), and consumers have a Markovian expectations function, denoted by $\Omega($.$) , which is a function of$ the same state variable, such that (i) given the consumers expectations function, starting from any (date, state) pair $(n, \Theta(n))$, the monopolist's strategy maximizes its profit, and (ii) given the monopolist's strategy, the consumers expectations are rational, i.e., their expectations are correct. Let us now define the state variable, the monopolist's strategy, and the consumers expectation function.

In any period $n, n=0,1,2,3 \ldots$, let $X(n) \in[0,1]$ denote the fraction of the total population (the customer base) that has purchased the product prior to that period, with $X(0)=0$. It may seem natural to use $X(n)$ as the state variable. However, it turns out to be more convenient to use as state variable the following monotone decreasing transformation of $X(n)$. We define the state variable $\Theta(n)$ by

$$
\Theta(n) \equiv F^{-1}(1-X(n)),
$$

where $F($.$) is the cumulative distribution of \theta$. Then $\Theta(0)=\bar{\theta} \equiv \theta_{0}$, and $\Theta(n) \in[\underline{\theta}, \bar{\theta}]$.

The firm's Markovian strategy is a pair $(\psi, \eta)$, that consists of two components: (a) a Markovian cut-off rule $\psi($.$) , specifying, at the be-$ ginning of period $n$, given $\theta_{n}$, what is the cut-off (on the distribution of consumers' types) that defines the targeted group of first-time customers for period $n$; and (b) a Markovian quality-schedule rule $\eta($.$) , specifying$ the monopolist's type-dependent quality offers to first-time consumers in period $n$.

To be more precise, in each period $n$, the firm's Markovian cut-off rule is a function $\psi($.$) that determines, for any currently-observed value$ $\Theta(n)$, a value $\Theta(n+1)=\psi(\Theta(n)) \leq \Theta(n)$, where $\psi($.$) is non-increasing$ and bounded below by $\underline{\theta}$. We interpret $\Theta(n+1)=\psi(\Theta(n))$ as the lowest-type of first-time consumers in period $n$ that the firm intends to serve.

A quality-schedule rule is a mapping $\eta($.$) that determines for any$ given $\Theta(n)$ an associated quality schedule $q_{n}(. \mid \Theta(n))$, which is itself a function that assigns to each $\theta \in[\Theta(n+1), \Theta(n)]$ a value in $\left[0, q_{\max }\right]$, where $\Theta(n+1)=\psi(\Theta(n))$. We interpret $q_{n}(\theta \mid \Theta(n))$ as the quality level offered to a first-time customer of type $\theta \in[\Theta(n+1), \Theta(n)]$ in period $n$, given that the value of the state variable is $\Theta(n)$.

On the consumers' side, their Markovian expectations rule $\Omega($.$) pre-$ dicts, given $\Theta(n)$, the life-time rent of the marginal first-time customer 
in period $n$, i.e., $U_{n}\left(\theta_{n+1}\right)$. When consumers have the ability to perfectly anticipate future market outcomes, condition (17) implies that the expectations function $\Omega($.$) must reflect rational expectations, i.e.,$

$$
\Omega(\Theta(n))=\sum_{j=1}^{\infty} \beta^{j}\left(\int_{\Theta^{*}(n+j+1)}^{\Theta^{*}(n+j)}\left[\frac{1-\beta}{r} q_{n+j}(s)\right] d s\right)=U_{n}\left(\theta_{n+1}\right),
$$

where $\left\{\Theta^{*}(.)\right\}_{n}^{\infty}$ is the path of the state variable $\Theta$ induced by the strategic behavior of the monopolist from period $n$, when the state variable takes the value $\Theta(n)$, and where $q_{n+j}(s)=q_{n+j}\left(s \mid \Theta^{*}(n+j)\right)$, i.e., the quality schedule that the consumers expect to be offered in period $n+j$ is the same as the schedule that the monopolist's equilibrium strategy would select. Note that, due to $(16), \Omega(\Theta(n))$ satisfies the following equation:

$$
\Omega(\Theta(n))=\beta\left(\Omega(\Theta(n+1))+\int_{\theta_{n+2}}^{\theta_{n+1}}\left[\frac{1-\beta}{r} q_{n+1}(s)\right] d s\right) .
$$

A Markovian strategy $(\eta(),. \psi()$.$) chosen by the monopolist is called$ a best reply to the consumer expectations function $\Omega($.) if (a) it yields a sequence of schedules $q_{n}($.$) and cut-off values \theta_{n+1}$ that maximize the monopolist's expected profits from any starting (date, state) pair $(n, \Theta(n))$, and (b) the rational expectations condition (24) is satisfied by such a sequence.

In what follows, we analyze in more detail the firm's optimal Markovian sales and quality strategies and characterize consumers' optimal Markovian expectation rules, under the assumptions that the distribution of $\theta$ is uniform and the production cost is quadratic.

\subsubsection{Equilibrium strategies under quadratic cost and uniform distribution}

In order to obtain a closed form solution for the firm's optimal strategy, in what follows, we suppose that the distribution of types is uniform on $[\underline{\theta}, \bar{\theta}]$ and that $c(q)$ is quadratic: $c(q)=\frac{\mu}{2} q^{2}, \mu>0$.

Because of the quadratic cost, the first best quality offered to old customers of type $\theta$ is $q^{*}(\theta)=\theta / \mu$. Then, using (2) and (3), the profit obtained in period $n$ from old customers is

$$
\Pi_{n}^{F} \equiv \frac{1-\beta}{r} \int_{\theta_{n}}^{\bar{\theta}} \pi^{F}(\theta) f(\theta) d \theta=\frac{1}{(\bar{\theta}-\underline{\theta})}\left(\frac{1-\beta}{6 \mu r}\left(\bar{\theta}^{3}-\Theta(n)^{3}\right)\right) .
$$

As for new customers, using eq. (22), where $\frac{F\left(\theta_{n}\right)-F(\theta)}{f(\theta)}=\theta_{n}-\theta$, the 
profit obtained in period $n$ from new customers in that period is

$$
\begin{aligned}
& I\left[\Theta(n), \Theta(n+1), q_{n}(. \mid \Theta(n))\right] \\
& \equiv \int_{\Theta(n+1)}^{\Theta(n)}\left\{\frac{1-\beta}{r}\left[\begin{array}{c}
(2 \theta-\Theta(n)) q_{n}(\theta \mid \Theta(n)) \\
-c\left(q_{n}(\theta \mid \Theta(n))\right)
\end{array}\right]-\Omega(\Theta(n))\right\} \frac{1}{(\bar{\theta}-\underline{\theta})} d \theta,
\end{aligned}
$$

where we have substituted $\Omega(\Theta(n))$ for $U_{n}\left(\theta_{n+1}\right)$ because of the rational expectations requirement.

It follows that the Bellman equation for the monopolist is

$$
V(\Theta(n))=\max _{q_{n}(.), \Theta(n+1)}\left\{\begin{array}{c}
\frac{(1-\beta)\left(\bar{\theta}^{3}-\Theta(n)^{3}\right)}{(\bar{\theta}-\underline{\theta}) 6 \mu r}+I\left[\Theta(n), \Theta(n+1), q_{n}(. \mid \Theta(n))\right] \\
+\beta V(\Theta(n+1))
\end{array}\right\},
$$

subject to the participation constraint (13), which is

$$
q_{n}\left(\theta_{n+1} \mid \Theta(n)\right)-\beta q_{n+1}\left(\theta_{n+1} \mid \Theta(n+1)\right) \geq 0 .
$$

(We will show subsequently that in the quadratic cost case, this constraint reduces to $\Theta(n+1) \geq \Theta(n) /(2-\beta)$ and that it is binding i.e., $\Theta(n+1)=\Theta(n) /(2-\beta)$, when the firm chooses its optimal response to the consumers' expectations rule.)

Consider for the moment any given sequence $\{\Theta(n)\}_{n=0}^{\infty}$ where $\Theta(n+$ $1) \leq \Theta(n)$. Given $\Theta(n)$, pointwise maximization of the RHS of the Bellman equation with respect to $q_{n}(\theta \mid \Theta(n))$ yields the necessary condition that determines the quality offered to first-time customers of type $\theta$ in period $n$ :

$$
q_{n}(\theta) \equiv q_{n}(\theta \mid \Theta(n))=c^{\prime-1}(2 \theta-\Theta(n)) \text { for all } \theta \in[\Theta(n+1), \Theta(n)]
$$

This is the standard static Mussa-Rosen quality schedule, conditional on $\Theta(n)$ being the highest type among period- $n$ new customers.

Thus, quality is strictly increasing in $\theta$, and there is no bunching. Since $c(q)$ is quadratic, equation (30) then implies that

$$
\mu q_{n}(\theta \mid \Theta(n))=2 \theta-\Theta(n) .
$$

For the highest-type among first-time customers in period $n$, we obtain

$$
\mu q_{n}(\Theta(n) \mid \Theta(n))=2 \Theta(n)-\Theta(n)=\Theta(n) .
$$

That is, the equilibrium quality offered to the highest type new customers in each period is such that the marginal cost of quality, which 
is given by $\mu q_{n}(\Theta(n) \mid \Theta(n))$, is exactly equal to their marginal valuation of quality, $\Theta(n)$. In other words, in our dynamic setting, in equilibrium there is no distortion at the top in each period. As we have argued before, with this non-distortion at the top result, the participation constraint (13) becomes (14). Since (31) implies that $\mu q_{n}(\Theta(n+1) \mid \Theta(n+1))=$ $\Theta(n+1)$ and $\mu q_{n}(\Theta(n+1) \mid \Theta(n))=2 \Theta(n+1)-\Theta(n)$, condition (14) is equivalent to

$$
\Theta(n+1) \geq \frac{1}{2-\beta} \Theta(n),
$$

meaning that the participation constraint imposes an upper limit on the rate at which the firm can expand its market coverage:

$$
\frac{\Theta(n)-\Theta(n+1)}{\Theta(n)} \leq 1-\frac{1}{2-\beta}
$$

Without loss of generality, we can set $\mu=1$. Then equation (30) reduces to

$$
q_{n}(\theta \mid \Theta(n))=2 \theta-\Theta(n) \text { for all } \theta \in[\Theta(n+1), \Theta(n)] .
$$

Equation (33) together with the participation constraint (32) imply that

$$
q_{n}\left(\theta_{n+1} \mid \Theta(n)\right)=2 \Theta(n+1)-\Theta(n) \geq\left(\frac{\beta}{2-\beta}\right) \Theta(n) .
$$

Lemma 2 below shows that the participation constraint (32) is binding. In order to derive this result, we assume for the moment that $\Omega^{\prime}(\Theta(n)) \geq 0$. We will show later that this condition holds in our closedform solution for the Markov Perfect Equilibrium of our dynamic game.

Lemma 2. Assume that $\Omega^{\prime}(\Theta(n)) \geq 0$. In the MPE, (i) the participation constraint is binding, with

$$
\Theta(n+1)=\Theta(n) /(2-\beta) .
$$

which implies that the quality offered to the marginal customer in period $n$ is distorted by a factor which is equal to the discount factor:

$$
q_{n}\left(\theta_{n+1} \mid \Theta(n)\right)=\left(\frac{\beta}{2-\beta}\right) \Theta(n)=\beta \Theta(n+1)
$$

And (ii) the monopolist's value function is decreasing in $\Theta(n): V^{\prime}(\Theta(n)) \leq$ 0 .

Proof. See the Appendix. 
Remark. The assumption that $\Omega^{\prime}(\Theta(n)) \geq 0$ is plausible: it says that consumers expect that higher type consumers have more informational rent than lower types and, as it will be shown later, such condition holds in our MPE. The result that $V^{\prime}(\Theta(n)) \leq 0$ is intuitively plausible. At the beginning of the program, i.e., at $n=0$, the state variable takes its highest value, $\Theta(0)=\bar{\theta}$, implying that the firm's data base about customers characteristics is empty. The size of this data base at the beginning of period $n$ is $\bar{\theta}-\Theta(n)$. As time goes on, $\Theta(n)$ takes on successively smaller values, meaning that the firm's data base with accurate information on customers' type gets bigger and bigger. (Such customers pay their maximum valuation of the product). Thus, the value of the firm is an increasing function of the size $\bar{\theta}-\Theta(n)$ of its data base, which explains why $V^{\prime}(\Theta(n))$ is negative.

Given the structure of the problem, i.e. a uniform distribution and a quadratic cost function, it is natural from now on to consider that the candidate cut-off rule of the monopolist is linear in the state

$$
\psi(\Theta(n))=\gamma \Theta(n),
$$

where $1 \geq \gamma \geq \frac{1}{2-\beta}$ (in view of the constraint (32)). Taking into account the fact that $\theta \in[\underline{\theta}, \bar{\theta}]$, we suppose that $\psi(\Theta(n))=\max [\underline{\theta}, \gamma \Theta(n)]$.

On the consumers' side, it is natural to look at candidate quadratic expectations function ${ }^{15}$

$$
\Omega(\Theta(n))=\lambda \Theta(n)^{2}
$$

Proposition 1 below provides an analytical characterization of the MPE (in closed-form solution) for the uniform distribution of consumers and quadratic costs of quality provision. In the case of the consumers' expectation function, it is worth noting that we obtain $\lambda>0$, guaranteeing that $\Omega^{\prime}(\Theta(n)) \geq 0$, as assumed in Lemma 2 .

Proposition 1. Under Assumption 3, if $\underline{\theta}=0$, there exists a MPE such that

$$
\gamma^{*}(\beta)=\frac{1}{2-\beta}
$$

and

$$
\lambda^{*}(\beta)=\frac{\beta(1-\beta)}{r(4-\beta)(2-\beta)^{2}} .
$$

\footnotetext{
${ }^{15}$ It is shown formally in the proof of Proposition 1 that no simple linear-quadratic expectations function my correspond to an MPE unless $\underline{\theta}=0$.
} 
Proof. See the Appendix.

Corollary 1. For $\bar{\theta}=1$, and $\underline{\theta}=0$ firm's maximum profits are equal to

$$
\Pi=\left(\frac{1}{6 r}\right) \frac{(2+\beta)(8+\beta(2 \beta-7))}{(4-\beta)(8+\beta(\beta-5))} .
$$

Proof. See Appendix.

\subsubsection{Non-Coasian dynamics}

In this subsection, we consider the effect of an exogenous decrease in the length of the interval of commitment $\Delta$ on the consumers' expectations of the informational rents of marginal customers, on the monopolist's profit and on the speed of market expansion.

What happens to the consumer equilibrium expectations coefficient, $\lambda$, when $\Delta$ shrinks? Noting that a decrease in $\Delta$ is equivalent to an increase in $\beta$, Figure 1 below shows the relationship between $r \lambda$ and $\beta$. (The parameter $\beta$ is measured the $x$-axis, while the $y$-axis displays $\lambda(\beta)$.The picture is drawn for $r=1$ ). The figure illustrates that $r \lambda$ evolves non-monotonically with $\beta$. It is at first increasing in $\beta$ and then 
decreasing. It is zero both when $\beta=0^{16}$ and when $\beta=1$. $^{17}$

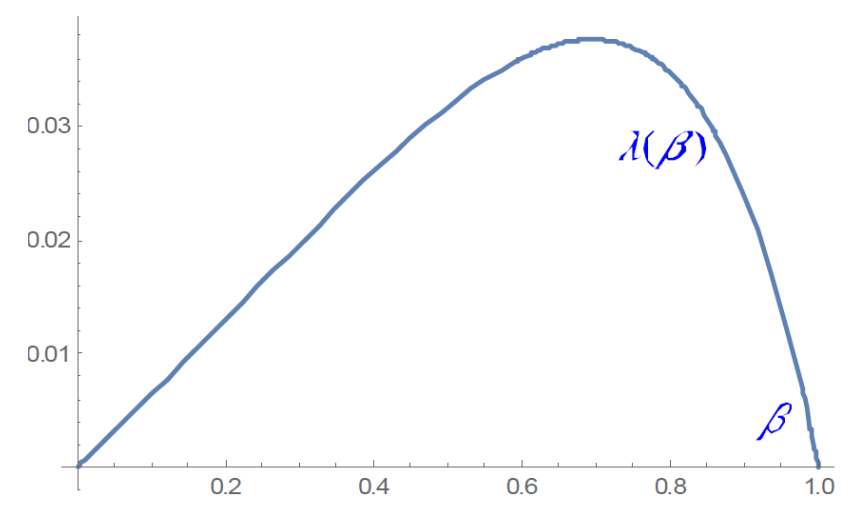

Figure 1. Equilibrium $\lambda(\beta)$

The relationship between $\Pi$ and $\beta$ is pictured in Figure 2 below. ${ }^{18}$ The parameter $\beta$ is measured along in the $x$-axis, while the $y$-axis displays $\Pi(\beta)$.The aggregate profit is increasing in $\beta$, i.e., it increases as the length of the period $\Delta$ of commitment shrinks. The intuition is as follows. The smaller $\Delta$ is, the faster the firm is able to collect Big Data about consumers' preferences. Thus, the smaller $\Delta$ is, the quicker the first-time customers become "old customers", from whom the surplus is fully extracted, thus enhancing the monopolist's profit.

\footnotetext{
${ }^{16}$ As $\beta \rightarrow 0$ (meaning $\Delta \rightarrow \infty$, i.e., the commitment interval is infinite), we see $\gamma \rightarrow 1 / 2$ and $\lambda \rightarrow 0$. This means that when the commitment period is infinite, the firm serves only customers whose type $\theta$ belongs to $\left[\frac{1}{2} \bar{\theta}, \bar{\theta}\right]$, and the rent of the lowest type that is served by the firm, type $\theta_{c}=(1 / 2) \bar{\theta}$, is zero.

${ }^{17}$ The intuition is that when the period of commitment shrinks to zero, the length of time over which the marginal new customers may derive some positive surplus by delaying their purchase to the next period becomes infinitesimal (notice that they are left with no surplus in the following period).

${ }^{18}$ The picture is drawn for $r=1$. Alternatively, the picture may also be interpreted as representing $r \Pi(\beta)$ for any value of $r$.
} 


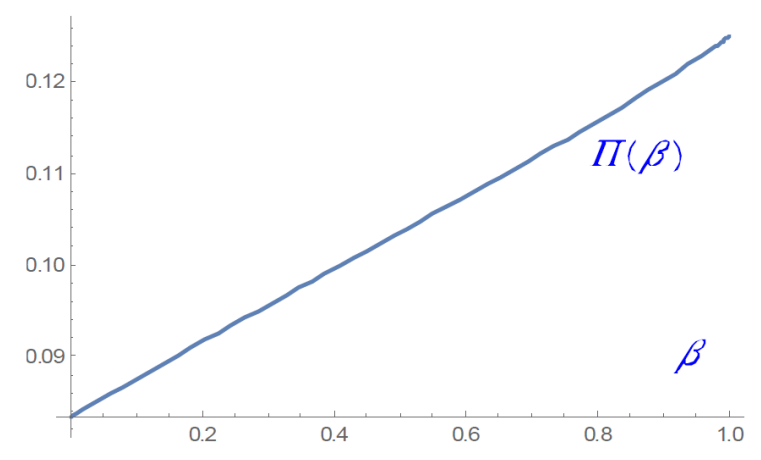

Figure 2. Equilibrium $\Pi(\beta)$

Assuming $\underline{\theta}=0$, the maximum possible market size is $\bar{\theta}-\underline{\theta}=\bar{\theta}$. The measure of customers that have been served at the end of period $n$ is $(1-$ $\left.\gamma^{n+1}\right) \bar{\theta}$. Thus the market is gradually fully covered only asymptotically, as $n$ tends to infinity. Our eventual full coverage result provides a sharp contrast to the static equilibrium case (the Mussa-Rosen case) and, as we shall show in Section 5, also to the dynamic case with full commitment, as in both of these cases only partial coverage occurs (under Assumption A3).

What about the speed at which the market is covered? How does it depend on the length of the period of commitment, $\Delta$ ? Let $t$ be a continuous variable denoting time, where $t=0$ is the beginning of period 0 (which is the first period), and, more generally, $t=n \Delta$ at the beginning of period $n$. Recall that $\gamma=1 /(2-\beta)$ and $\beta \equiv e^{-r \Delta}$. Accordingly, the extent of market coverage, i.e., the number of consumers who do consume the good, $\left(1-\gamma^{n+1}\right) \bar{\theta}$, can be expressed as a function of $t$, given $\Delta$ and $r$ :

$$
M(t ; \Delta, r) \equiv\left[1-\left(\gamma\left(e^{-r \Delta}\right)\right)^{\frac{t}{\Delta}+1}\right] \bar{\theta} .
$$

What happens to $M(t ; \Delta, r)$ when the length of the commitment period, $\Delta$, shrinks? Given $r$, a decrease in $\Delta$ is an increase in $\beta$. The shrinking of $\Delta$ have two opposite effects. On one hand, since $\gamma^{\prime}(\beta)>0$, a shortening of $\Delta$ will result in an increase in $\gamma$, i.e., the market expansion from one period to the next, as measured by $\left(\theta_{n}-\theta_{n+1}\right) / \theta_{n}=1-\gamma$, is smaller when the firm can more rapidly gather information on consumers' tastes (so that $\Delta$ is smaller). On the other hand, when the interval between two periods becomes smaller, over any time interval $[0, t]$ market expansions occur more often. 
It turns out that the market coverage is generically a hump-shaped function of $\Delta$. Starting at a small $\Delta$, a marginal lengthening of $\Delta$ will increase $M$, until some critical value $\Delta_{c}(t)$ is reached, beyond which a further lengthening of $\Delta$ will reduce $M$. The critical value $\Delta_{c}(t)$ is smaller for larger values of $t$. A shortening of the period of commitment first speeds up market coverage but eventually slows it down. This is pictured in the Figure 3 below, where the downward-sloping line $\Delta_{c}(t)$ is defined for $t$ in a certain range. In the figure, the $y$-axis measures $t$, whereas the $x$-axis measures $\Delta$. In the region where $(\Delta, t)$ lies above (below) the downward-sloping line $\Delta_{c}(t)$, we obtain that a marginal increase in $\Delta$ slows down (speeds up) market coverage.

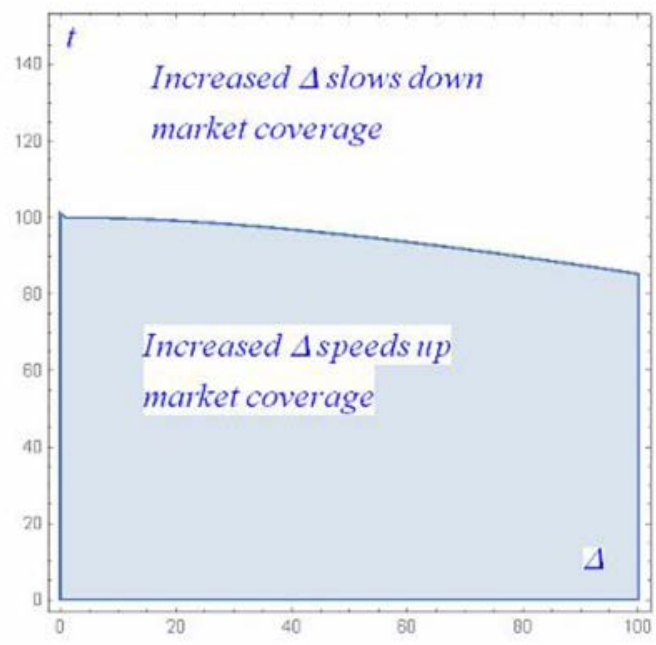

Figure 3. The effects of $\Delta$ on market coverage $(r=0.01)$

To get an intuition of this result, let us compare the two limiting cases. As $\Delta$ becomes arbitrarily small, we show in Claim 2 below that market expansion occurs progressively and eventually all the market is covered, though in infinite time. At the other extreme, when $\Delta=+\infty$, half of the market is instantaneously covered but there is no further market coverage. Accordingly the initial market coverage greater in the latter case but after some time has elapsed, the market coverage under small $\Delta$ overtakes the market coverage under large $\Delta$ : lower types eventually buy the good whereas they would be excluded from the market in the case $\Delta \rightarrow \infty$. 
Notice that under no circumstances there would be full market coverage at the initial instant. As we state in Claim 2 below, full coverage never occurs instantaneously, even when the length of time $\Delta$ between two different proposals to two consecutive sets of new customers becomes infinitesimal.

Claim 2. Under Assumption 3, even when the length of time $\Delta$ between two offers to two consecutive sets of new customers becomes infinitesimal, the market is never covered instantaneously. For any given time $t>0$, as the length of the period of commitment $\Delta$ tends to 0 , the number of customers that have been served up to that time tends to $\left(1-e^{-r t}\right) \bar{\theta}$ :

$$
\lim _{\Delta \rightarrow 0}\left(1-\left(\gamma\left(e^{-r \Delta}\right)^{\frac{t}{\Delta}+1}\right) \bar{\theta}=\left(1-e^{-r t}\right) \bar{\theta} .\right.
$$

Proof. See the Appendix.

From Claim 2, it follows that equilibrium dynamics are clearly nonCoasian ${ }^{19}$ since the market never happens to be covered in a "twinkling of an eye". In our model, market expansion occurs progressively. In addition, full market coverage may occur in equilibrium, though only in infinite time. In the following section we compare our results to a benchmark model addressing the case in which the firm is able to commit to future sales plans.

\section{Commitment to Future Sales Plans}

Suppose now that, contrary to what has been assumed in the preceding sections, the monopolist is able to commit, right from the beginning, to offer a sequence of pre-determined contracts. ${ }^{20}$ This commitment capability is supposed to include the ability to commit both with regard to new customers and to former customers. Thus, at time $t=0$, the monopolist announces (i) the old-customer contracts it will offer at any future period $n+j(j=1,2,3 \ldots)$ to consumers who first purchase the good in period $n$; and (ii) the new-customer contracts to consumers who have not already purchased the good (and consequently the firm cannot identifies them since it has not yet had the possibility to collect data about their tastes).

\footnotetext{
${ }^{19}$ Recall that Coase (1972) argues that if the durable-good monopolist can supply to a new set of customers after selling to the previous set of customers, then, if the time interval that must elapse between two consecutive offers decreases to zero, the whole market will be covered in a twinkle of an eye.

${ }^{20}$ The contracts proposed to a given consumer are, as in the non-commitment case, fixed (but now announced at time $t=0$ and irrevocably committed to) for periods of fixed length $\Delta$.
} 
Let us consider now the case of consumers who are first-time buyers in period $n$. They face (i) a contract offer $\left(q_{n}^{N}(\widehat{\theta}), p_{n}^{N}(\widehat{\theta})\right)$, which depends on their reported type $\widehat{\theta}$ when buying for the first time in period $n$ and (ii) a contract offer $\left(q_{n}^{O}(\theta), p_{n}^{O}(\theta)\right)$ for purchasing in all the remaining periods. Here, the superscripts $N$ and $O$ stand for "new customers" and "old customers" respectively. ${ }^{21}$ These contract offers are determined and announced from the outset, i.e., at time $t=0$. We assume that the monopolist can commit not to make any change in the future to these pre-determined contracts. A possible commitment device could be to sign up ad-eternum fidelity contracts in which the price-quality offers change once if the consumer stays with the firm for more than a given time period (which would be equal to $\Delta$ in the context of our model). If such fidelity contracts could be enforced in court, then they could work as a commitment device. However, since these contracts must last forever (which is not too realistic), the model with commitment to future sales plans presented in this section should be interpreted as a theoretical benchmark rather than a realistic market description.

A type $\theta$-customer who makes the first purchase in period $n$, where $\theta \in\left[\theta_{n+1}, \theta_{n}\right]$, would be willing to report her true type iff

$$
\theta=\arg \max _{\widehat{\theta}} \frac{1-\beta}{r}\left(\theta q_{n}^{N}(\widehat{\theta})-p_{n}^{N}(\widehat{\theta})\right) .
$$

Note that this equation is the same as eq. (4).

Denoting by $U_{n}(\theta \mid C)$ the life-time net utility of a consumer of type $\theta$ who buys the good for the first time in period $n$ under the commitment scenario, i.e., given that the monopolist is able to commit to a predetermined sequence of contracts. Then

$$
U_{n}(\theta \mid C)=\max _{\widehat{\theta}} \frac{1-\beta}{r}\left(\theta q_{n}^{N}(\widehat{\theta})-p_{n}^{N}(\widehat{\theta})\right) .
$$

The envelope theorem implies that the contract offers are incentive compatible iff

$$
U_{n}^{\prime}(\theta \mid C)=\frac{1-\beta}{r} q_{n}^{N}(\theta)
$$

Accordingly, by integrating, we obtain, for all $\theta \in\left[\theta_{n}, \theta_{n+1}\right]$,

$$
U_{n}(\theta \mid C)=U_{n}\left(\theta_{n+1} \mid C\right)+\int_{\theta_{n+1}}^{\theta}\left(\frac{1-\beta}{r} q_{n}^{N}(s)\right) d s
$$

\footnotetext{
${ }^{21}$ Allowing contract offers to old customers to be possibly different across periods would not change the results.
} 
where the second term of the RHS is the difference between the life-time net utility of a high-type first-time consumer in period $n$ and that of the marginal first-time consumer in period $n$.

In addition, a well-known revealed preference argument leads to the result that $U_{n}(\theta \mid C)$ is convex:

$$
U_{n}^{\prime \prime}(\theta \mid C)=\frac{1-\beta}{r} q_{n}^{N^{\prime}}(\theta) \geq 0 .
$$

The participation constraint for consumers who choose to be a firsttime buyer in period $n$ is that they do not gain by delaying their first purchase to period $n+1$, i.e.,

$$
U_{n}(\theta \mid C) \geq \beta\left[\frac{1-\beta}{r}\left(\theta q_{n+1}^{N}(\theta)-p_{n+1}^{N}(\theta)\right)\right] .
$$

Using the same argument as in the proof of Claim 1, it is easy to show that, if a consumer $\theta \in\left[\theta_{n+1}, \theta_{n}\right]$ were to deviate from buying for the first time in period $n$, her best deviation, when buying in period $n+1$, would be to claim that her type is $\widehat{\theta}=\theta_{n+1}$. Accordingly, the participation constraint (40) for a type $\theta \in\left[\theta_{n+1}, \theta_{n}\right]$ may be written as

$$
\Delta_{n}(\theta \mid C) \equiv U_{n}(\theta \mid C)-\beta\left(\frac{1-\beta}{r}\left(\theta q_{n+1}^{N}\left(\theta_{n+1}\right)-p_{n+1}^{N}\left(\theta_{n+1}\right)\right)\right) \geq 0
$$

Since $\theta_{n+1}$ is the type who is indifferent between buying for the first time at $n$ and buying for the first time at $n+1$, it must be the case that $\Delta_{n}\left(\theta_{n+1} \mid C\right)=0$, i.e., given (38),

$$
\begin{aligned}
U_{n}\left(\theta_{n+1} \mid C\right) & =\beta\left(\frac{1-\beta}{r}\left(\theta q_{n+1}^{N}\left(\theta_{n+1}\right)-p_{n+1}^{N}\left(\theta_{n+1}\right)\right)\right) \\
& =\beta\left(U_{n+1}\left(\theta_{n+2} \mid C\right)+\int_{\theta_{n+2}}^{\theta_{n+1}}\left[\frac{1-\beta}{r} q_{n+1}^{N}(\theta)\right] d \theta\right), \\
& =\sum_{j=1}^{\infty} \beta^{j}\left(\int_{\theta_{n+j+1}}^{\theta_{n+j}}\left[\frac{1-\beta}{r} q_{n+j}^{N}(\theta)\right] d \theta\right) .
\end{aligned}
$$

From the facts that $\Delta_{n}(\theta \mid C)$ is a convex function of $\theta$ and that $\Delta_{n}(\theta \mid C) \geq \Delta_{n}\left(\theta_{n+1} \mid C\right)=0$ for all $\theta \in\left[\theta_{n+1}, \theta_{n}\right]$, it follows that condition (41) is satisfied iff, in addition to condition (42), the following inequality is met:

$$
\Delta_{n}^{\prime}(\theta \mid C)=\frac{1-\beta}{r}\left(q_{n}^{N}\left(\theta_{n+1}\right)-\beta q_{n+1}^{N}\left(\theta_{n+1}\right)\right) \geq 0 .
$$


The aggregate profit (discounted to the beginning of period $n$ ) which the monopolist makes from vintage-n consumers (i.e., from those who are first-time consumers in period $n$ ) over their whole life time is

$$
\begin{aligned}
\pi_{n}= & \int_{\theta_{n+1}}^{\theta_{n}}\left[\frac{1-\beta}{r}\left(p_{n}^{N}(\theta)-c\left(q_{n}^{N}(\theta)\right)\right] f(\theta) d \theta\right. \\
& +\beta \int_{\theta_{n+1}}^{\theta_{n}}\left[\frac{p_{n}^{O}(\theta)-c\left(q^{O}(\theta)\right)}{r}\right] f(\theta) d \theta .
\end{aligned}
$$

Clearly, $\pi_{n}$ is the sum of the profit in period $n$ when the consumers $\theta \in\left[\theta_{n+1}, \theta_{n}\right]$ buy for the first time (the first integral) plus the present value of all the profits in all the subsequent periods (the second integral). By a now familiar argument, $\pi_{n}$ can be rewritten as

$$
\pi_{n}=\int_{\theta_{n+1}}^{\theta_{n}}\left[\begin{array}{c}
\frac{1-\beta}{r}\left(\theta q_{n}^{N}(\theta)-c\left(q_{n}^{N}(\theta)\right)\right. \\
+\frac{\beta}{r}\left(\theta q_{n}^{O}(\theta)-c\left(q_{n}^{O}(\theta)\right)-U_{n}(\theta \mid C)\right.
\end{array}\right] f(\theta) d \theta
$$

Notice that the bracketed term equals aggregate social surplus over a type $\theta$ customer minus her net utility; it is thus the profit the firm makes from a type $\theta$ customer.

Integration by parts, using (37) and (38), yields

$$
\begin{aligned}
\pi_{n} & =\int_{\theta_{n+1}}^{\theta_{n}}\left[\frac{1-\beta}{r}\left(\left(\theta-\frac{F\left(\theta_{n}\right)-F(\theta)}{f(\theta)}\right) q_{n}^{N}(\theta)-c\left(q_{n}^{N}(\theta)\right)\right)\right] f(\theta) d \theta \\
& +\int_{\theta_{n+1}}^{\theta_{n}}\left[\frac{\beta}{r}\left(\theta q_{n}^{O}(\theta)-c\left(q_{n}^{O}(\theta)\right)-U_{n}\left(\theta_{n+1} \mid C\right)\right] f(\theta) d \theta\right.
\end{aligned}
$$

where $U_{n}\left(\theta_{n+1} \mid C\right)$ is given by equation (42). The aggregate discounted profits from period 0 is the sum of discounted profits from all vintages:

$$
\Pi^{C} \equiv \sum_{n=0}^{\infty} \beta^{n} \pi_{n}
$$

Using (42), this can be written as

$$
\Pi^{C}=\sum_{n=0}^{\infty} \beta^{n}\left\{\int_{\theta_{n+1}}^{\theta_{n}}\left[\begin{array}{c}
\frac{1-\beta}{r}\left((\theta-h(\theta)) q_{n}^{N}(\theta)-c\left(q_{n}^{N}(\theta)\right)\right. \\
+\frac{\beta}{r}\left(\theta q_{n}^{O}(\theta)-c\left(q_{n}^{O}(\theta)\right)\right.
\end{array}\right] f(\theta) d \theta\right\}
$$

For any given sequence $\left\{\theta_{n}\right\}_{n=0}^{\infty}$ with $\theta_{n+1} \leq \theta_{n}$, maximizing $\Pi^{C}$ with respect to $q_{n}^{N}(\theta)$ and $q_{n}^{O}(\theta)$, we obtain the following result: 
Lemma 3. When the monopolist is able to commit to future sales, then, for any given sequence $\left\{\theta_{n}\right\}_{n=0}^{\infty}$ with $\theta_{n+1} \leq \theta_{n}$,

(i) all consumers whose type $\theta$ is in $\left[\theta_{c}, \bar{\theta}\right)$, where $\theta_{c}-h\left(\theta_{c}\right)=0$, are offered distorted qualities $q_{n}^{N}(\theta)=q^{* *}(\theta), \forall n \geq 0$, when they purchase for the first time, where $q^{* *}(\theta)$ is defined by $q^{* *}(\theta)=c^{-1}(\theta-h(\theta))$ for $\theta>\theta_{c}$. There is no distortion for the highest type $\bar{\theta}$.

(iii) in any period $n>1$, all former consumers are offered the corresponding first-best quality level $q_{n}^{O}(\theta)=q^{*}(\theta)$, where $q^{*}(\theta)=c^{\prime-1}(\theta)$.

Proof. See the Appendix.

The higher a new consumer's type is, the higher the quality she is offered. Notice that this is simply the equilibrium quality schedule of the static Mussa-Rosen model. As stated in Lemma 3, the monopolist offers a higher quality level to old customers than to new ones: this is because it is optimal to distort downward the quality offered to new customers in order to induce them not to under-report their types. This incentive disappears for former customers because they are identified by the firm after their first purchase and thus cannot subsequently misreport their type.

Using Lemma 3 to substitute for $q_{n}^{N}(\theta)$ and $q_{n}^{O}(\theta)$ in $\Pi^{C}$, and then maximizing $\Pi^{C}$ with respect to $\theta_{n}$ and $\theta_{n+1}$, where $n=1,2,3 \ldots$, we finally obtain $\theta_{n}=\theta_{c}, \forall n \geq 1$. That is, the optimal sequence $\left\{\theta_{n}^{*}\right\}_{n=0}^{\infty}$ is $\left\{\theta_{c}, \theta_{c}, \theta_{c}, \ldots, \theta_{c}, \ldots\right\}$. This means that, in period 0 , every customer whose type $\theta$ belongs to the interval $\left[\theta_{c}, \bar{\theta}\right]$ is offered a corresponding quality level $q^{* *}(\theta)$, and for all the remaining periods they are offered the first-best quality $q^{*}(\theta)$.

As can be seen from eq. (38) evaluated at $n=0$ and $\theta_{1}=\theta_{c}$, in equilibrium, all consumers with $\theta \in\left[\theta_{c}, \bar{\theta}\right]$ make their purchase in every period, and they derive a life time net utility:

$$
U_{0}(\theta \mid C)=\frac{1-\beta}{r} \int_{\theta_{c}}^{\theta} q^{* *}(s) d s, \text { where } \theta \in\left[\theta_{c}, \bar{\theta}\right] .
$$

Using (36) evaluated at $n=0$, and (45) we find that the price first-time consumers pay for a unit of quality $q(\theta)$ is $p^{* *}(\theta)=\theta q^{* *}(\theta)-r U_{0}(\theta \mid C)=$ $\theta_{c} q^{* *}(\theta)$, implying strictly positive informational rent for all $\theta>\theta_{c}$.

Proposition 2. If the monopolist can commit right from the start to any sequence of contract offers, then starting at time $t=0$, it is optimal to expand the market immediately in the initial period, so that all consumers with type $\theta \in\left[\theta_{c}, \bar{\theta}\right]$ are served in period $n=0$, and consumers whose types are inferior to $\theta_{c}$ are excluded. There are no market expansions in subsequent periods. Moreover, 
(i) in period 0 , the customer types $\theta \in\left[\theta_{c}, \bar{\theta}\right]$ are offered the contract $\left(q^{* *}(\theta), p^{* *}(\theta)\right)$,

(ii) in all subsequent periods, they are offered the contract $\left(q^{*}(\theta), p^{*}(\theta)\right)$, which constitutes a quality upgrade, but fully extracts the consumers' surplus.

Proof. See the Appendix.

However, the optimal strategy in the game with commitment is not time-consistent. In other words, if at some future time the firm is released from its commitment, it will have an incentive to deviate from the initial plan. Indeed, when allowed to change its offers to potential new customers in subsequent periods, it would benefit from selling to at least to some of the previously unserved customers, i.e., those with $\theta<\theta_{c}$, in order to track them and identify their preferences (so that the firm could subsequently extract their whole surplus by making a personalized quality-price offer). Rational customers who expect to benefit from better offers in the future would then delay their purchase to the next period unless they are granted lower present prices (higher rents). ${ }^{22}$

In the simple case of an uniform distribution with $\underline{\theta}=0$ and $\bar{\theta}=1$, the monopolist's profit under commitment are obtained as

$$
\Pi^{C}=\frac{1}{r}\left[(1-\beta) \frac{1}{12}+\beta \frac{7}{48}\right] .
$$

Upon observation, it is easy to conclude that $\Pi^{C}$ increasing in $\beta$, that is decreasing in $\Delta$. The reason is obvious: the smaller is the period $\Delta$ over which the firm is unable to identify consumer's type (because it is still gathering and processing information on the consumers) the quicker it can switch from second to first-order price discrimination. Comparing (46) with profits under non commitment (34) confirms that the profit under commitment is higher.

\section{Welfare analysis}

In this section, we analyze how consumers' surplus and total welfare are affected by the speed at which firms are able to identify consumers' types through Big Data collection (which, in our model, is measured by the parameter $\Delta$ ). This allows us to shed some light on the market

\footnotetext{
${ }^{22}$ A monopolist that can commit is in effect an "open-loop Stackelberg leader," and it is well-known that open-loop Stackelberg leaders are typically beset by timeinconsistency problem. For more detailed discussion, see Chapter 5 of Dockner et al. (2000), and Chapter 1 of Long (2010).
} 
effects that are possibly associated with recent policies limiting firms' ability to collect information on consumers (e.g. The EU's General Data Protection Regulation (GDPR) policy), which end up affecting in an important way the length over which firms remain unable to completely identify their consumers' tastes.

For the sake of simplicity, in order to permit easier comparisons across different scenarios about the length of the commitment period, we specialize here to the linear-quadratic case with $\bar{\theta}=1$ and $\underline{\theta}=0$. Let us first start with the case in which the monopolist is unable to commit to future sales contracts and let us denote by $w(n)$ the social welfare at the MPE in period $n$, defined as the sum of the gross utility of old customers and new customers, net of production costs. Using (26) and (30), we can express $w(n)$ as follows: ${ }^{23}$

$$
w(n)=\frac{1-\beta}{r}\left[\begin{array}{c}
\frac{1}{6}\left(1-\Theta(n)^{3}\right) \\
+\int_{\gamma \Theta(n)}^{\Theta(n)}\left(\theta(2 \theta-\Theta(n))-\frac{1}{2}(2 \theta-\Theta(n))^{2}\right) d \theta
\end{array}\right] .
$$

The aggregate discounted social welfare is then simply $\sum_{n=0}^{\infty} \beta^{n} w(n)$. Since $\Theta(n)=\gamma^{n}$, we obtain

$$
W(\beta)=\frac{6+\beta(-2+\beta(\beta-2))}{6 r(8+\beta(\beta-5))} .
$$

Welfare $W(\beta)$ is a non-monotonic function of $\beta$ (and of $\Delta$ ) which takes the same minimum value $\frac{1}{8 r}$ for $\beta=0(\Delta=+\infty)$ and $\beta=1$ $(\Delta=0)$. It takes its maximum value $\left(\frac{0.134064}{r}\right)$ for $\beta \simeq 0.477727$, or, equivalently, $\Delta=\frac{0.718}{r}$. This is the length of contractual commitment which a benevolent regulator would (should) select.

There are indeed two opposite effects. On one hand, the smaller $\Delta$ is, the more rapidly the highest type first-time customers in each period are offered their first best quality level, which has a positive effect on welfare. However there is another effect that works in the opposite direction: a reduction of $\Delta$ slows down the expansion of the market so that lower types of consumers must wait longer for the opportunity to purchase. At $\Delta=\frac{0.718}{r}$, the regulator strikes the right balance between these two opposite effects. Figure 4 illustrates this point. The $x$-axis in the figure represents $\beta$, whereas the $y$-axis displays $W(\beta)$. The figure is drawn for

\footnotetext{
${ }^{23}$ Note that the profit derived from the old customers in period $n$ is equal to their gross utility (which is fully appropriated by first-degree price discrimination) minus the production costs.
} 
$r=1$.

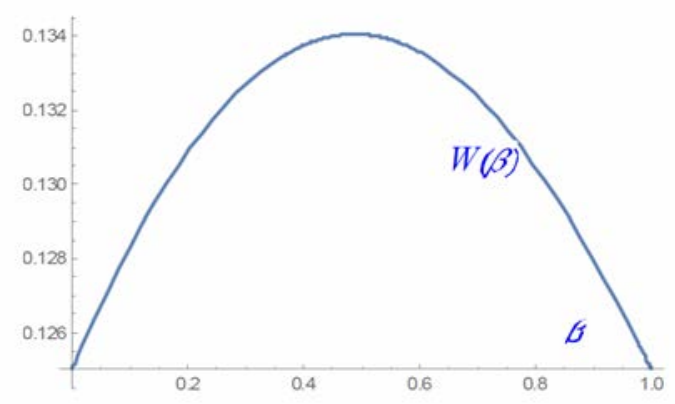

Figure 4. Equilibrium $W(\beta)$.

Finally, let us consider the effect of a decrease in $\Delta$ on the aggregate consumer surplus, denoted by $C S$. Clearly, $C S$ is the difference between $W(\beta)$ and $\Pi(\beta)$ :

$$
C S(\beta)=\frac{(1-\beta)\left(8+\beta^{2}(\beta-3)\right)}{r(4-\beta)(8+\beta(\beta-5))} .
$$

This is a decreasing function of $\beta$, or equivalently, an increasing function of $\Delta$. The intuition is straightforward: the greater is $\Delta$, the longer the time firms need to get full information about consumers preferences and, therefore, the longer the length of the period over which new customers may derive a positive net utility from consumption. This result is illustrated in Figure 5 below. The $x$-axis in the figure represents $\beta$, whereas the $y$-axis displays $C S(\beta)$. The figure is drawn for $r=1$.

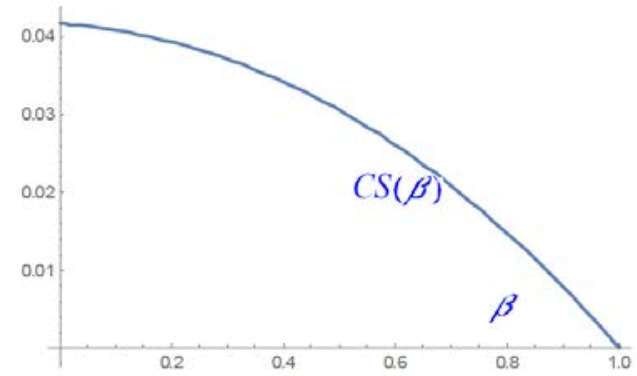

Figure 5. Equilibrium $C S(\beta)$.

Our welfare analysis shows that the interests of the monopolist and the customers with respect to the length of the contractual commitment 
period are diametrically opposed: the monopolist favors the shortest possible one (since this means that the full identification of the new consumers' types would be the fastest possible) while the consumers benefit from the longest possible one.

It is also worth investigating whether the monopolist's ability to commit to future sales could enhance (or reduce welfare). In order to answer this question, note that the aggregate consumer surplus under commitment is

$$
C S^{C}=\frac{1-\beta}{24 r} .
$$

which is decreasing in $\beta$, or increasing in $\Delta$. Welfare under commitment is

$$
W^{C}(\beta)=\Pi^{C}+C S^{C}=\frac{1-\beta}{8 r}+\frac{7 \beta}{48 r},
$$

which is increasing in $\beta$ (i.e., it is decreasing in $\Delta$ ), with $W^{C}(0)=$ $1 / 8 r$ and $W^{C}(1)=7 / 48 r$. The intuition is that with $\Delta=0$, the (type-dependent) first-best optimal quality is offered to customers $\theta \in$ $\left[\frac{1}{2}, 1\right]$ from the outset. Comparing the welfare under commitment with the welfare under non-commitment (see Figure 6 below), the latter is greater for low values of $\beta \leq \frac{3}{7}$ (large values of $\Delta$ ) and smaller for values

of $\beta \geq \frac{3}{7}$ (small values of $\Delta$ ). The maximum welfare is obtained in the commitment scenario when the length of the period of contractual commitment is minimum $(\Delta=0)$.

\section{Conclusion}

We have developed a dynamic version of Mussa and Rosen (1978) product quality model, in which a monopolist sells over an infinite number of periods a vertically differentiated non-durable good to consumers. The monopolist has access to modern data collection technologies which allow them to track the preferences of consumers after their first purchase (e.g. using cookies in online websites or requiring type-specific information when offering consumers the possibility to adhere to fidelity membership programmes).

The firm, initially uninformed about the consumers' type-specific preferences, is able to offer at each period a (different) price-quality schedule to first-time customers as a screening mechanism. Once the firm collects information about their preferences, it switches from seconddegree to first-degree price discrimination, using the information on consumers' preferences to implement hyper-segmentation strategies based on personalized price/quality offers to its old customers.

A crucial assumption of our model is that the monopolist can identify a consumer's type once he/she has purchased the good for the first time. 
This means that buyers can cheat the seller (by misreporting) only once. After the contractual period for first-time customers has elapsed, the firm will make personalized price-quality offers so that old customers of any given type will only be offered their corresponding non-distorted quality level at a price that completely extracts their surplus.

After enjoying consumer's surplus during the period in which the consumer has the "new customer" status, when she returns to the firm in subsequent periods for additional purchases (under the status of an old consumer), she benefits from a quality upgrade. However, at the same time, she also has to pay a higher (type-specific) personalized price for these purchases. As a result, all the consumer's surplus ends up being extracted by the firm.

One of our major findings is that the market dynamics arising in our model is non-Coasian (if not anti-Coasian): the market is never covered instantaneously and the monopolist's aggregate profit increases (while the consumers' surplus decreases) when the length of the period of contractual commitment decreases. Hence, our model predicts that the monopolist actually benefits from technological innovations that allow it to gather and process more rapidly accurate information about consumers' type-specific tastes.

It is important to note that what prevents instantaneous market coverage in our set-up is the new customers' participation constraint: they should not benefit from delaying their first purchase to the next period. If they deviate, they could buy the (first-best) quality good offered in the next period to the highest type among next period's first-time customers rather than the lower quality one which the firm offers them at the present moment. In order to make this deviation unprofitable, the monopolist must limit market expansion from one period to the next.

Another important result is the conflict of interests between the firm and the consumers regarding the length of the period of contractual commitment. While the firm would favor the shortest possible one, consumers prefer it to be the longest possible, in order to limit firms' ability to track their true type (and use such information to implement quality-price personalized offers that fully extract consumers' surplus). We show that, as a result, aggregate social surplus is a non-monotonic function of the period of commitment between two contract offers. Social welfare is maximized at a positive but finite value of the time needed to gather information on consumers' type (which can be interpreted as the period of commitment or the time it takes for a new consumer to become an old one). This may provide some guidance for regulatory policy. When the period of contractual commitment $\Delta$ is too long, high type consumers will be served sooner but that will unduly delay the 
moment at which low type customers will purchase the good. A too short period of commitment has the opposite effects.

Finally we studied the commitment benchmark, in which the monopolist can commit, right from the start, to offer to its customers a sequence of pre-determined contracts. Exactly as in the non-commitment scenario, former customers are offered the first-best optimal qualities but at prices which transfer all the surplus to the firm. So, the monopoly exploits in both cases all the information it is able to gather through big data on its first-time buyers. The difference is that, under commitment, the price-quality schedule offered to first-time customers is time-invariant, so that there will be no new first-time customers after the initial period. This is intended to deter high type customers from waiting before buying the good. In contrast, in the non-commitment case, they rationally expect that new offers will be subsequently made so that the monopolist must grant them greater rents to dissuade them from waiting.

It would be interesting to extend the model to the case of duopoly with horizontally differentiated products, where each firm produces a range of vertically differentiated quality levels. If one duopolist refrains from information acquisition, would it be in the interest of the other firm to acquire information? And if both acquire information, would they both be worse-off, as it is often the case with personalized prices? ${ }^{24}$

Finally, we note that in the present paper there are no data collection costs, nor information storage costs. It would be interesting to work on an extension of the model, where firms would have to pay to know about consumers' tastes, in a dynamic setting. ${ }^{25}$ If this was the case and if firms could get information on only a fraction of the market (and not on all the consumers who buy), would it still be true that firms would be hurt by price discrimination through customer recognition? By leaving out a fraction of customers with unknown preferences, could the firm be better off or would it always prefer not to discriminate? This question would be an interesting subject for future research.

\section{References}

[1] Acquisti, A. and H. Varian (2005), Conditioning Prices on Purchase History. Marketing Science 24(3): 367-381.

\footnotetext{
${ }^{24}$ See, for example Thisse and Vives (1988) for a model in which the prisoners' dilemma outcome arises when both firms have the possibility to engage in price personalization strategies.

${ }^{25}$ In a static setting, Chen et al. (2001) allowed competing firms to make their investment decisions to acquire targetability. They found that a prisoner dilemma occurs when targetability in a market is sufficient high.
} 
[2] Bond, E., and L. Samuelson, (1987), The Coase conjecture need not hold for durable good monopolies with depreciation. Economics Letters 24:93-97.

[3] Bulow, J. I., 1982, "Durable Goods Monopolists", Journal of Political Economy, 90(2), 314-32.

[4] Coase, R., 1972, "Durability and Monopoly, Journal of Law and Economics, 15, 143-149.

[5] Chen, Y. (2005), Oligopoly Price Discrimination by Purchase History. Pros and Cons of Price Discrimination, Ch.4 (Swedish Competition Authority, Stockholm).

[6] Chen, Y., C. Narasimhan, and Z. J. Zhang (2001), Individual Marketing with Imperfect Marketability. Marketing Science, Vol. 20(1), 23-41.

[7] Chen, Y., \& Iyer, G. (2002). Research note consumer addressability and customized pricing. Marketing Science, 21(2), 197-208.

[8] Choe, C., S. King, N. Matsushima (2018), Pricing with Cookies: Behavior-Based Price Discrimination and Spatial Price Competition. Management Science 64(12): 5669-5687.

[9] Dockner, E., S. Jorgensen, N. V. Long, and G. Sorger (2000), Differential Games in Economics and Management Science. Cambridge University Press, Cambridge, U.K.

[10] Driskill, R. and S. McCafferty, (2001) Monopoly and oligopoly provision of addictive goods. International Economic Review 42(1): 43-72.

[11] Fudenberg, D., \& Tirole, J. (2000), Customer poaching and brand switching. RAND Journal of Economics, 634-657.

[12] Fudenberg, D., \& Villas-Boas, J. M. (2006), Behavior-based price discrimination and customer recognition. Handbook on economics and information systems, 1, 377-436.

[13] Golosov, M., N. Kocherlakota, and A.Tsyvinski (2003), "Optimal Indirect and Capital Taxation," Review of Economic Studies 70(3): 569-587.

[14] Golosov, M., M. Troskin, and A.Tsyvinski (2016), "Redistribution and Social Insurance." American Economic Review, 106(2): 359386.

[15] Holmstrom, B., (1977), On Incentives and Control in Organizations. Ph.D. Thesis, Standford University.

[16] Jing, B. (2017), Behavior-Based Pricing, Production Efficiency, and Quality Differentiation. Management Science 63(7): 2365-2376.

[17] Kahn, C., 1987, "The Durable Goods Monopolist and Consistency with Increasing Costs," Econometrica, 54, 274-294.

[18] Karp, L., (1996), Depreciation erodes the Coase conjecture. Euro- 
pean Economic Review 40: 473-490.

[19] Kemp, M.C. and N.V. Long (1980), "Optimal Tariff and Exhaustible Resources," Essay 16 in M. C. Kemp and N. V. Long (Eds.), Exhaustible Resources, Optimality and Trade, North Holland Publishing Company, Amsterdam and New York.

[20] Kocherlakota, N. (2005), "Zero Expected Wealth Taxes: A Mirrlees Approach to Dynamic Optimal Taxation," Econometrica, 73(5): 1587-1621.

[21] Kydland, F. and E.C. Prescott (1977), "Rules Rather than Discretion: The Inconsistency of Optimal Plans," Journal of Political Economy 85:473-491.

[22] Laffont, J.-J. and J. Tirole, (1986), Using Cost Observations to Regulate Firms, Journal of Political Economy, 94: 614-641.

[23] Laffont, J.-J. and J. Tirole, (1988), The Dynamics of Incentive Contracts, Econometrica, 56, 1153-1175.

[24] Laffont, J.-J. and D. Martimore, (2002), The Theory of Incentives: The Principal-Agent Model, Princeton University Press.

[25] Laussel, D., M. de Montmarin, and N. V. Long, (2004), Dynamic duopoly with congestion effects. International Journal of Industrial Organization 22 (5): 655-677.

[26] Laussel, D., N. V. Long and J. Resende (2015), Network Effects, Aftermarkets and the Coase Conjecture. International Journal of Industrial Organization, Vol. 41: 84-96.

[27] Laussel, D. and J. Resende (2019), "Product Personalization and Behavior Based Price Discrimination", mimeo

[28] Lederer, J. P. and A. P. Hurter (1986). Competition of Firms: Discriminatory Pricing and Location. Econometrica 54(3): 623-640.

[29] Long, N. V. (2010), A Survey of Dynamic Games in Economics. World Scientific Publishers, Singapore and London.

[30] Long, N. V., (2015), Dynamic Games Between Firms and Infinitelylived Consumers: A Review of the Literature. Dynamic Games and Applications, Vol. 5(4): 467-492.

[31] Martimort, D. (2006), Multi-contracting mechanism design, in: Advances in economics and econometrics, Vol. 1., Cambridge University Press: 57-101.

[32] Maskin, E. and D. Newbery (1990), "Disadvantageous Oil Tariffs and Dynamic Consistency," American Economic Review 80(1): 143-156.

[33] Mason, R. (2000) Network externalities and the Coase conjecture. European Economic Review 44: 1981-1992.

[34] Mirrlees, J. A. (1971), "An Exploration in the Theory of Optimum Income Taxation", Review of Economic Studies, 38, 175-208. 
[35] Mussa, M., \& Rosen, S. (1978). Monopoly and product quality. Journal of Economic Theory, 18(2), 301-317.

[36] Myerson, R. (1979), "Incentive-Compatibility and the Bargaining Problem." Econometrica 47, 61-73.

[37] Reinganum, J. F. and N. L. Stokey (1985), "Oligopoly Extraction of a Common Property Natural Resource: The Importance of Period of Commitment in Dynamic Games," International Economic Review 26: 161-173.

[38] Rhee, K.-E. and R. Thomadsen (2017), Behavior-Based Pricing in Vertically Differentiated Industries. Management Science 63(8): 2729-2740.

[39] Pazgal, A., \& Soberman, D. (2008). Behavior-based discrimination: Is it a winning play, and if so, when? Marketing Science, 27(6), 977-994.

[40] Stantcheva, S. (2017), Optimal Taxation and Human Capital Policies over Life Cycle. Journal of Political Economy 125(6): 19311190.

[41] Stokey, N., 1981, "Rational Expectations and Durable Goods Pricing," Bell Journal of Economics, 12, 112-128.

[42] Villas-Boas, J. M. (1999). Dynamic competition with customer recognition. The Rand Journal of Economics, 604-631.

\section{APPENDIX}

Derivation of the equation (22) for $\Pi_{n}^{N}$

By integrating the last terms in eq (21) by parts, we obtain

$$
\begin{aligned}
& -\int_{\theta_{n+1}}^{\theta_{n}} U_{n}(\theta) f(\theta) d \theta \\
& -\left[U_{n}\left(\theta_{n}\right) F\left(\theta_{n}\right)-U_{n}\left(\theta_{n+1}\right) F\left(\theta_{n+1}\right)\right]+\int_{\theta_{n+1}}^{\theta_{n}} U_{n}^{\prime}(\theta) F(\theta) d \theta
\end{aligned}
$$

where the integral on the RHS is equal to

$$
\int_{\theta_{n+1}}^{\theta_{n}}\left[\frac{1-\beta}{r} q_{n}(\theta)\right]\left(\frac{F(\theta)}{f(\theta)}\right) f(\theta) d \theta
$$

Thus $\Pi_{n}^{N}$ can be expressed as

$$
\begin{aligned}
\Pi_{n}^{N} & =\int_{\theta_{n+1}}^{\theta_{n}}\left[\frac{1-\beta}{r}\left(\theta q_{n}(\theta)-c\left(q_{n}(\theta)\right)+\frac{F(\theta)}{f(\theta)} q_{n}(\theta)\right)\right] f(\theta) d \theta \\
& -\left[U_{n}\left(\theta_{n}\right) F\left(\theta_{n}\right)-U_{n}\left(\theta_{n+1}\right) F\left(\theta_{n+1}\right)\right]
\end{aligned}
$$


Now, the second term on the RHS of (48) can be written as

$$
\begin{aligned}
& {\left[U_{n}\left(\theta_{n+1}\right) F\left(\theta_{n+1}\right)-U_{n}\left(\theta_{n+1}\right) F\left(\theta_{n}\right)\right]} \\
& +\left[U_{n}\left(\theta_{n+1}\right) F\left(\theta_{n}\right)-U_{n}\left(\theta_{n}\right) F\left(\theta_{n}\right)\right]
\end{aligned}
$$

which is equal to $-U_{n}\left(\theta_{n+1}\right) \int_{\theta_{n+1}}^{\theta_{n}} f(\theta) d \theta-F\left(\theta_{n}\right) \int_{\theta_{n+1}}^{\theta_{n}} U_{n}^{\prime}(\theta) d \theta$.

This is, in turn, equal to

$$
-\int_{\theta_{n+1}}^{\theta_{n}} U_{n}\left(\theta_{n+1}\right) f(\theta) d \theta-\int_{\theta_{n+1}}^{\theta_{n}}\left(\frac{F\left(\theta_{n}\right)}{f(\theta)}\right)\left[\frac{1-\beta}{r} q_{n}(\theta)\right] f(\theta) d \theta .
$$

After substitution, we obtain the equation (22) for $\Pi_{n}^{N}$.

\section{Proof of Claim 1}

Incentive compatibility at $n+1$ implies that if a consumer is of type $\theta_{n+1}$, then reporting any $\theta^{\prime}<\theta_{n+1}$ would not be optimal, i.e.,

$$
\begin{aligned}
& \frac{1-\beta}{r}\left(\theta_{n+1} q_{n+1}\left(\theta_{n+1}\right)-p_{n+1}\left(\theta_{n+1}\right)\right) \\
\geq & \frac{1-\beta}{r}\left(\theta_{n+1} q_{n+1}\left(\theta^{\prime}\right)-p_{n+1}\left(\theta^{\prime}\right)\right), \forall \theta^{\prime} \leq \theta_{n+1}
\end{aligned}
$$

And any type- $\theta$ consumer such that $\theta>\theta_{n+1}$ who deviates to be firsttime consumers in period $n+1$ would obtain a net utility at least as high as that of a consumer of type $\theta_{n+1}$ who is a first-time customer in period $n+1$ :

$$
\begin{aligned}
& \frac{1-\beta}{r}\left(\theta q_{n+1}\left(\theta_{n+1}\right)-p_{n+1}\left(\theta_{n+1}\right)\right) \\
\geq & \frac{1-\beta}{r}\left(\theta_{n+1} q_{n+1}\left(\theta_{n+1}\right)-p_{n+1}\left(\theta_{n+1}\right)\right), \forall \theta \geq \theta_{n+1}
\end{aligned}
$$

Combining the two inequalities, we find that $\forall \theta \geq \theta_{n+1}$ and $\forall \theta^{\prime} \leq$ $\theta_{n+1}$,

$$
\begin{aligned}
& \frac{1-\beta}{r}\left(\theta q_{n+1}\left(\theta_{n+1}\right)-p_{n+1}\left(\theta_{n+1}\right)\right) \\
& \geq \frac{1-\beta}{r}\left(\theta_{n+1} q_{n+1}\left(\theta^{\prime}\right)-p_{n+1}\left(\theta^{\prime}\right)\right) .
\end{aligned}
$$

Consequently, $\widetilde{\theta}(\theta)=\theta_{n+1}$ for all $\theta \in\left[\theta_{n+1}, \theta_{n}\right]$

\section{Proof of Lemma 1}


From (6), (10) and (12), $\Delta_{n}(\theta)$ is a convex function. Accordingly, since $\Delta_{n}\left(\theta_{n+1}\right)=0$, if follows that $\Delta_{n}(\theta) \geq 0 \forall \theta \in\left[\theta_{n+1}, \theta_{n}\right]$ iff $\Delta_{n}^{\prime}\left(\theta_{n+1}\right) \geq$ 0 . Let us determine the sign of $\Delta_{n}^{\prime}\left(\theta_{n+1}\right)$. From (6) and (12),

$$
\begin{aligned}
\Delta_{n}^{\prime}(\theta) & =U_{n}^{\prime}(\theta)-\beta\left(\frac{1-\beta}{r} q_{n+1}\left(\theta_{n+1}\right)\right) \\
& =\frac{1-\beta}{r} q_{n}(\theta)-\beta\left(\frac{1-\beta}{r} q_{n+1}\left(\theta_{n+1}\right)\right)
\end{aligned}
$$

Evaluating $\Delta_{n}^{\prime}(\theta)$ at $\theta=\theta_{n+1}$, we obtain

$$
\Delta_{n}^{\prime}\left(\theta_{n+1}\right)=\frac{1-\beta}{r}\left(q_{n}\left(\theta_{n+1}\right)-\beta q_{n+1}\left(\theta_{n+1}\right)\right) .
$$

It follows that condition stated in Lemma 1 is necessary and sufficient for the participation constraint $\Delta_{n}(\theta) \geq 0$ (for all $\theta \in\left[\theta_{n+1}, \theta_{n}\right]$ ) to be satisfied.

\section{Proof of Lemma 2}

Using (30) in the expression of $I\left[\Theta(n), \Theta(n+1), q_{n}(. \mid \Theta(n))\right]$, presented in eq. (27), we can rewrite the RHS of the Bellman equation (28) as

$$
\begin{aligned}
v(\Theta(n), \Theta(n+1)= & \frac{1}{(\bar{\theta}-\underline{\theta})}\left(\int_{\Theta(n+1)}^{\Theta(n)}\left[\frac{1-\beta}{2 r}(2 \theta-\Theta(n))^{2}-\Omega(\Theta(n))\right] d \theta\right) \\
& +\frac{(1-\beta)\left(\bar{\theta}^{3}-\Theta(n)^{3}\right)}{(\bar{\theta}-\underline{\theta}) 6 r}+\beta V(\Theta(n+1)) .
\end{aligned}
$$

The monopolist, taking the consumers' expectation rule $\Omega($.$) as given,$ maximizes the above expression with respect to $\Theta(n+1)$, subject to the participation constraint (32). Let $\kappa \geq 0$ be the Kuhn-Tucker multiplier associated with the constraint that $\Theta(n+1)-\frac{1}{2-\beta} \Theta(n) \geq 0$.

The FOC with respect to $\Theta(n+1)$ subject to $\Theta(n+1)-\frac{1}{2-\beta} \Theta(n) \geq 0$ is obtained as

$$
\begin{aligned}
& \frac{1}{(\bar{\theta}-\underline{\theta})}\left[-\frac{1-\beta}{2 r}(2 \Theta(n+1)-\Theta(n))^{2}+\Omega(\Theta(n))\right]+ \\
& \beta V^{\prime}(\Theta(n+1))+\kappa=0,
\end{aligned}
$$

with

$$
\kappa \geq 0, \Theta(n+1)-\frac{1}{2-\beta} \Theta(n) \geq 0, \lambda\left[\Theta(n+1)-\frac{1}{2-\beta} \Theta(n)\right]=0 .
$$


Differentiating the Bellman equation with respect to $\Theta(n)$, and using the envelope result, we obtain

$$
V^{\prime}(\Theta(n))=\frac{1}{(\bar{\theta}-\underline{\theta})}\left(\begin{array}{c}
-\Omega(\Theta(n))+ \\
\int_{\Theta(n+1)}^{\Theta(n)}\left[-\frac{1-\beta}{r}(2 \theta-\Theta(n))-\Omega^{\prime}(\Theta(n))\right] d \theta
\end{array}\right) .
$$

It follows that:

$$
\begin{aligned}
& V^{\prime}(\Theta(n+1))= \\
= & \frac{1}{(\bar{\theta}-\underline{\theta})}\left(\begin{array}{c}
-\Omega(\Theta(n+1))+ \\
\int_{\Theta(n+2)}^{\Theta(n+1)}\left[-\frac{1-\beta}{r}(2 \theta-\Theta(n+1))-\Omega^{\prime}(\Theta(n+1))\right] d \theta
\end{array}\right)
\end{aligned}
$$

i.e.,

$$
\begin{aligned}
& \beta V^{\prime}(\Theta(n+1))= \\
& \frac{-\beta}{(\bar{\theta}-\underline{\theta})}\left(\begin{array}{c}
\Omega(\Theta(n+1))+\int_{\theta_{n+2}}^{\theta_{n+1}}\left[\frac{1-\beta}{r}(2 \theta-\Theta(n+1))\right] d \theta \\
+\Omega^{\prime}(\Theta(n+1))[\Theta(n+1)-\Theta(n+2)]
\end{array}\right)
\end{aligned}
$$

Then, with the help of (25), if $\beta>0$, the above expression reduces to

$$
\begin{array}{r}
\beta V^{\prime}(\Theta(n+1))= \\
-\frac{1}{(\bar{\theta}-\underline{\theta})} \Omega(\Theta(n))-\frac{1}{(\bar{\theta}-\underline{\theta})} \Omega^{\prime}(\Theta(n+1))[\Theta(n+1)-\Theta(n+2)] \leq 0
\end{array}
$$

where we have made use of the assumption that $\Omega^{\prime}() \geq$.0 . Substituting this expression for $\beta V^{\prime}(\Theta(n+1))$ into (49), the FOC becomes:

$$
\begin{aligned}
& -\frac{(1-\beta)(2 \Theta(n+1)-\Theta(n))^{2}}{2 r}- \\
& \Omega^{\prime}(\Theta(n+1))[\Theta(n+1)-\Theta(n+2)]+(\bar{\theta}-\underline{\theta}) \kappa=0 .
\end{aligned}
$$

Thus, as long as $1 \geq \beta>0$, this condition is satisfied if and only if $\kappa>0$ and we conclude that the participation constraint $\Theta(n+1)-$ $\frac{1}{2-\beta} \Theta(n) \geq 0$ holds with equality at the optimal solution. (Note that this proof does not rely on the supposition that the monopolist uses a linear cut-off rule, and does not assume that $\Omega($.$) is quadratic).$

\section{Proof of Proposition 1}

We conjecture an equilibrium pair of strategies $(\psi, \Omega)$ where $\psi$ is linear and $\Omega($.$) is quadratic, \Omega(\Theta(n))=\lambda \Theta(n)^{2}+B$ with $\lambda \geq 0$, where $B$ is some constant. (It is verified below that $\lambda>0$.) Then $\Omega^{\prime}(\Theta(n)) \geq 0$, and from Lemma 2, the participation constraint is binding, $\Theta(n+1)=$ 
$\Theta(n) /(2-\beta)$. Thus, for our linear cut-off rule to be optimal, we must have $\gamma=1 /(2-\beta)$. On the consumers' expectations function, there is an obvious requirement: if the lowest type to be served as first-time customers in period $n$ is $\Theta(n+1)=\underline{\theta}$, then it must hold these new consumers enjoy zero informational rent, i.e.,

$$
U_{n}(\underline{\theta})=0
$$

Now, if $\Theta(n+1)=\underline{\theta}$, then it must hold that

$$
\Theta(n)=\psi^{-1}(\underline{\theta})=\underline{\theta} / \gamma
$$

From (24) and (51), the following boundary condition must hold

$$
\Omega(\underline{\theta} / \gamma)=0 .
$$

Equation (52) says that if $\Theta(n)=\underline{\theta} / \gamma$, then consumers expect that $U_{n}(\Theta(n+1))=U_{n}(\underline{\theta})=0$. Taking into account the boundary condition $(52)$, we conjecture that

$$
\Omega(\Theta(n))=\lambda \Theta(n)^{2}-\lambda(\underline{\theta} / \gamma)^{2}
$$

so that if $\theta_{n}=\underline{\theta} / \gamma$, then there is no informational rent for the marginal consumers in period $n$ (who are of type $\underline{\theta}$, and they indifferent between being first-time buyers in period $n$ versus being first-time buyers in period $n+1)$. Given the monopolist's cut-off parameter $\gamma$ and his quality-schedule (33), using our conjectured expectations rule (53), the rational expectations requirement (24), with the help of equation (16), can be rewritten as

$$
\begin{aligned}
& \lambda\left[\Theta(n)^{2}-(\underline{\theta} / \gamma)^{2}\right] \\
= & \beta\left(\lambda\left[\Theta(n+1)^{2}-(\underline{\theta} / \gamma)^{2}\right]+\int_{\Theta(n+2)}^{\Theta(n+1)} \frac{1-\beta}{r}(2 \theta-\Theta(n+1)) d \theta\right)(55)
\end{aligned}
$$

Using the conjectured equilibrium cut-off rule, we have $\Theta(n+1)=\gamma \Theta(n)$ and $\Theta(n+2)=\gamma^{2} \Theta(n)$, and equation (54) becomes

$$
\begin{aligned}
& \lambda\left[\Theta(n)^{2}-(\underline{\theta} / \gamma)^{2}\right] \\
= & \beta \lambda\left(\gamma^{2} \Theta(n)^{2}-(\underline{\theta} / \gamma)^{2}\right)+\beta \int_{\gamma^{2} \Theta(n)}^{\gamma \Theta(n)} \frac{(1-\beta)}{r}(2 \theta-\gamma \Theta(n)) d \theta
\end{aligned}
$$

Unfortunately, this conjecture does not work if $\underline{\theta} \neq 0$, because eq. (56) involves two groups of terms. One group has $\Theta(n)^{2}$ as the common 
factor, while the second group (which does not contain $\left.\Theta(n)^{2}\right)$ requires that

$$
-\lambda(\underline{\theta} / \gamma)^{2}=-\beta \lambda(\underline{\theta} / \gamma)^{2}
$$

which is impossible to be satisfied, unless $\underline{\theta}=0$. Thus, in what follows, we assume that $\underline{\theta}=0$. Upon evaluating the integral on the RHS of eq. (56), we obtain the relationship between the monopolist's cut-off parameter $\gamma$ and the consumers' expectations parameters $\lambda$ :

$$
\left(1-\beta \gamma^{2}\right) \lambda-\frac{1}{r}\left(\beta(1-\beta)(1-\gamma) \gamma^{3}\right)=0
$$

or, equivalently,

$$
r \lambda=\frac{\beta(1-\beta)(1-\gamma) \gamma^{3}}{1-\beta \gamma^{2}}
$$

Plugging in $\gamma=\frac{1}{2-\beta}$ in (59), we obtain the result in Proposition 1 .

Proof of Corollary 1

To compute the monopolist's optimal profit, let us conjecture that the value function is cubic. We guess that

$$
V\left(\theta_{n}\right)=\frac{1}{6 r \bar{\theta}}\left[\bar{\theta}^{3}-z \theta_{n}^{3}\right]
$$

where $z$ is to be determined. Recall that the equilibrium cut-off rule is linear and the equilibrium expectations function is quadratic. Then, it must be the case that

$$
\beta V\left(\theta_{n+1}\right)=\beta V\left(\gamma \theta_{n}\right)=\frac{\beta}{6 r \bar{\theta}}\left[\bar{\theta}^{3}-z \gamma^{3} \theta_{n}^{3}\right]
$$

implying:

$$
V\left(\theta_{n}\right)-\beta V\left(\theta_{n+1}\right)=\frac{1}{6 r \bar{\theta}}(1-\beta) \bar{\theta}^{3}-\frac{\theta_{n}^{3} z\left(1-\beta \gamma^{3}\right)}{6 r \bar{\theta}}
$$

On the other hand, from the Bellman equation, $V\left(\theta_{n}\right)-\beta V\left(\theta_{n+1}\right)$ must be equal to:

$$
\frac{(1-\beta)\left(\bar{\theta}^{3}-\Theta(n)^{3}\right)}{6 r \bar{\theta}}+\frac{1}{\bar{\theta}}\left(\int_{\theta_{n+1}}^{\theta_{n}}\left[\frac{1-\beta}{2 r}\left(2 \theta-\theta_{n}\right)^{2}-\lambda \theta_{n}^{2}\right] d \theta\right)
$$

To evaluate the integral, we use the conjectured cut-off rule $\theta_{n+1}=\gamma \theta_{n}$. Note that $\left(2 \theta-\theta_{n}\right)^{2}=4 \theta^{2}+\theta_{n}^{2}-4 \theta_{n} \theta$, and the antiderivative of the RHS is $\frac{4}{3} \theta^{3}+\theta_{n}^{2} \theta-2 \theta_{n} \theta^{2}$. 
Then the integral in expression (62) is given by:

$$
\frac{1}{\bar{\theta}}\left(\frac{1-\beta}{2 r}\right) \theta_{n}^{3}\left(\frac{4}{3}\left(1-\gamma^{3}\right)+(1-\gamma)-2\left(1-\gamma^{2}\right)\right)-\frac{\lambda \theta_{n}^{3}}{\bar{\theta}}(1-\gamma)
$$

Equating the two expressions for $V\left(\theta_{n}\right)-\beta V\left(\theta_{n+1}\right)$, i.e., equating the RHS of (61) and the RHS of (62), we get

$$
\begin{aligned}
& \frac{1}{6 r \bar{\theta}}(1-\beta) \bar{\theta}^{3}-\frac{\theta_{n}^{3} z\left(1-\beta \gamma^{3}\right)}{6 r \bar{\theta}}= \\
= & \frac{(1-\beta)\left(\bar{\theta}^{3}-\theta_{n}^{3}\right)}{6 r \bar{\theta}}+\left[\begin{array}{c}
\frac{1}{\bar{\theta}}\left(\frac{1-\beta}{2 r}\right) \theta_{n}^{3}\left(\frac{4}{3}\left(1-\gamma^{3}\right)+(1-\gamma)-2\left(1-\gamma^{2}\right)\right) \\
-\frac{\lambda \theta_{n}^{3}}{\bar{\theta}}(1-\gamma)
\end{array}\right]
\end{aligned}
$$

Thus we have

$$
\begin{aligned}
& \frac{-z\left(1-\beta \gamma^{3}\right)}{6 r}= \\
= & \frac{-(1-\beta)}{6 r}+\left(\frac{1-\beta}{2 r}\right)\left(\frac{4}{3}\left(1-\gamma^{3}\right)+(1-\gamma)-2\left(1-\gamma^{2}\right)\right)-\lambda(1-\gamma) .
\end{aligned}
$$

Solving for $z$, we obtain

$$
z=\frac{\left((1-\beta) \gamma\left(3-6 \gamma+4 \gamma^{2}\right)+6 r \lambda(1-\gamma)\right)}{1-\beta \gamma^{3}}
$$

It follows that

$V(\Theta(n))=\frac{1}{6 r(\bar{\theta}-\underline{\theta})}\left[\bar{\theta}^{3}-\frac{\left((1-\beta) \gamma\left(3-6 \gamma+4 \gamma^{2}\right)+6 r \lambda(1-\gamma)\right)}{1-\beta \gamma^{3}} \Theta(n)^{3}\right]$

Thus the firm's profit is

$$
\Pi=V(\bar{\theta})=\frac{\bar{\theta}^{3}}{6 r \bar{\theta}}[1-z]
$$

Setting $\bar{\theta}=1$, then

$$
\Pi=\frac{1}{6 r}(1-z)=\frac{1}{6 r}\left(1-\frac{(1-\beta) \gamma\left(3-6 \gamma+4 \gamma^{2}\right)+6 r \lambda(1-\gamma)}{\left(1-\beta \gamma^{3}\right)}\right)
$$

Then substituting for $\gamma$ and for $r \lambda$ in (63) their equilibrium values and simplifying, we get:

$$
\Pi=\left(\frac{1}{6 r}\right) \frac{(2+\beta)(8+\beta(2 \beta-7))}{(4-\beta)(8+\beta(\beta-5))} .
$$


as stated in Corollary 1.

\section{Proof of Claim 2}

Since $\gamma(1)=1, \lim _{\Delta \rightarrow 0}\left(\gamma\left(e^{-r \Delta}\right)\right)^{\frac{t}{\Delta}+1}=\lim _{\Delta \rightarrow 0}\left(\gamma\left(e^{-r \Delta}\right)\right)^{\frac{t}{\Delta}}$. Notice that $\ln \left(\gamma\left(e^{-r \Delta}\right)\right)^{\frac{t}{\Delta}}=\frac{t}{\Delta} \ln \left(\gamma\left(e^{-r \Delta}\right)\right)$. Since that $\gamma(1)=1, \frac{t}{\Delta} \ln \left(\gamma\left(e^{-r \Delta}\right)\right)$ is undefined when $\Delta=0$. Then, in order to determine the limit value of $\frac{\ln \left(\gamma\left(e^{-r \Delta}\right)\right)}{\Delta}$ when $\Delta \rightarrow 0$, we have to use L'Hopital's rule and evaluate the ratio of the derivatives of the numerator and the denominator at $\Delta=0$. This ratio turns out to be equal to $-r \gamma^{\prime}(1)$. It follows that $\lim _{\Delta \rightarrow 0}\left(\gamma\left(e^{-r \Delta}\right)\right)^{\frac{t}{\Delta}}=e^{-r \gamma^{\prime}(1) t}$.

Now let us determine $\gamma^{\prime}(1)$. Given that $\gamma(\beta)=\frac{1}{2-\beta}, \gamma^{\prime}(\beta)=\frac{1}{(2-\beta)^{2}}$ and, accordingly, $\gamma^{\prime}(1)=1$. We conclude that $\lim _{\Delta \rightarrow 0}\left(\gamma\left(e^{-r \Delta}\right)\right)^{\frac{t}{\Delta}}=e^{-r t}$.

\section{Proof of Lemma 3}

Point-wise maximization of $\Pi^{C}$ with respect to the quality levels $q_{n}^{N}(\theta)$, subject to $q_{n}^{N}(\theta) \geq 0$, leads to

1. $q_{n}^{N}(\theta)=q^{* *}(\theta), \forall n \geq 0$, where $q^{* *}(\theta)$ is the solution of

$$
\theta-h(\theta)-c^{\prime}\left(q^{* *}(\theta)\right) \leq 0 \text {, with equality holding if } q^{* *}(\theta)>0 .
$$

Similarly, $q_{n}^{O}(\theta)=q^{*}(\theta), \forall n \geq 0$, where $q^{*}(\theta)$ is the solution of (1), i.e., to each type, the monopolist offers the corresponding first-best quality level.

\section{Proof of Proposition 2}

It only remains to show that the constraint (43) is satisfied. Given that $q_{n}^{N}\left(\theta_{n+1}\right)=q_{n+1}^{N}\left(\theta_{n+1}\right)=q_{n}^{O}\left(\theta_{n+1}\right)=q_{n+1}^{O}\left(\theta_{n+1}\right)=q^{*}\left(\theta_{n+1}\right)$, this is trivially the case. 